\title{
LA INTERVENCIÓN EN EL TEMPLO DE SANTA ANA DEL CUSCO ${ }^{[*]}$
}

\author{
THE ARCHITECTURAL INTERVENTION IN THE SANTA ANA CHURCH OF CUSCO \\ GERMÁN ZECENARRO BENAVENTEE ${ }^{[\star \star}$, VÍCTOR MANUEL SALAS VELÁSQUEZ ${ }^{(\star \star \star]}$ \\ Y NILDA LILIANA VALVERDE CCANNIHUA ${ }^{(\star \star \star *)}$
}

Fecha de recepción: 31 de marzo de 2017

Fecha de aprobación: 19 de mayo de 2017

\section{RESUMEN}

El presente artículo aborda el análisis crítico de las intervenciones de conservación y restauración realizadas por el Ministerio de Cultura (durante el periodo 2006-2012) en el templo de Santa Ana del Cusco (Perú). Se ponderan los aciertos y la coherencia de sus resultados y logros, así como también se manifiesta la omisión de un planteamiento integral para la restitución de la concepción completa del edificio, a fin de elaborar un cuerpo de experiencias metodológicas que expresen los aspectos que conllevaron a la recuperación integral de los testimonios materiales y los valores implícitos del monumento, dentro del panorama de la conservación patrimonial que se realiza en la ciudad del Cusco y su región. Se analizan los aspectos de la intervención que posibilitaron la recuperación de la volumetría y el espacio interior del monumento, así como se observa la carencia de planteamientos sobre el espacio del atrio del templo, los cuales hubieran podido articularse desde el punto de vista de la gestión, con proyectos de recuperación del ambiente urbano inmediato emprendidos por la autoridad municipal.

\section{PALABRAS CLAVE}

Patrimonio, restauración, monumento religioso del Cusco

\section{ABSTRACT}

This article addresses and explains the critical analysis of the conservation and restoration interventions carried out by the Ministry of Culture (in the period between 2006 and 2012) in the Santa Ana Church of Cusco (Peru). The achievements are weighed, as well as the coherence of its results and achievements, and their absences in terms of the restitution of the full conception of the building. This is done in order to have a body of methodological experiences that express the aspects that led to the comprehensive recovery of its material testimonies and the implicit values of the monument, within the panorama of the patrimonial conservation realized in the city of Cusco and the region. This article analyzes the aspects of the intervention that enabled the recovery of the volumetrics and the interior space of the monument. It also observes the lack of proposals about the space of the temple's atrium, which could have been articulated from the point of view of management, with projects for the recovery of the adjacent urban environment undertaken by the municipal authority.

\section{KEYWORDS}

Heritage, restoration, religious monument of Cusco

(*) El presente artículo fue elaborado a partir de la investigación titulada Metodología de Intervención en el Patrimonio Inmueble: El Templo de Santa Ana del Cusco (2006-2012), desarrollada en el Taller de Conservación del Patrimonio Arquitectónico, dirigido por el Msc. Arq. José Hayakawa Casas, en la Maestría de Arquitectura, mención en Gestión del Patrimonio Cultural, Centros y Sitios Históricos de la Universidad Nacional San Antonio Abad del Cusco (UNSAAC) (2017). $\left.{ }^{(* *}\right)$ Arquitecto por la UNSAAC. Estudios de segunda especialidad en Restauración de Bienes Culturales Muebles e Inmuebles, y estudios de maestría en Arquitectura con mención en Gestión del Patrimonio Cultural, Centros y Sitios Históricos en la misma universidad. Miembro de la Oficina Técnica del Centro Histórico del Cusco, Acuerdo Municipalidad del Cusco - Agencia Española de Cooperación Internacional para el Desarrollo, y especialista en temas de arquitectura prehispánica e historia del arte cusqueño. Docente del área de Historia de la Arquitectura en la Facultad de Arquitectura e Ingeniería Civil de la UNSAAC. Contacto: german.zecenarrob@unsaac.edu.pe

$\left.{ }^{(* *}\right)$ Arquitecto por la UNSAAC. Candidato a maestro en Ciencias con mención en Arquitectura-Vivienda, Sección de Posgrado y Segunda Especialización de la Universidad Nacional de Ingeniería. Cursa la maestría en Arquitectura con mención en Gestión del Patrimonio Cultural, Centros y Sitios Históricos de la UNSAAC. Docente del área de Diseño Arquitectónico y Edificaciones en la Facultad de Arquitectura e Ingeniería Civil de la UNSAAC, y la Escuela Profesional de Arquitectura en Universidad Andina del Cusco. Contacto: vicmansave@hotmail.com (****) Arquitecta por la UNSAAC. Estudios de segunda especialidad en Restauración de Bienes Culturales Muebles e Inmuebles y estudios de maestría en Arquitectura con mención en Gestión del Patrimonio Cultural, Centros y Sitios Históricos en la UNSAAC. Arquitecta especialista en Gestión del Riesgo de Desastres en el Patrimonio Cultural, en el Área Funcional de Defensa Nacional de la Dirección Desconcentrada de Cultura Cusco. Contacto: liliamsss@hotmail.com 


\section{Estudio histórico y arquitectónico del Templo de Santa Ana del Cusco}

El Templo de Santa Ana del Cusco es uno de los monumentos religiosos representativos del periodo virreinal peruano. Forma parte del acervo patrimonial de la antigua ciudad capital de los Incas, la cual se emplaza a 3,350 m.s.n.m., en la zona andina de la región suroriental del Perú.

Esta edificación se encuentra en el sector noroccidental de la ciudad, conocido desde tiempos de los incas como Karmenqa, sitio con significativa antigüedad de ocupación en el valle del Cusco (Zecenarro, 2007). En este lugar se han hallado evidencias de asentamientos humanos desde el periodo Formativo (Barreda, 1994)-como es el caso de Chanapata (800 a. n. E.)- hasta el Horizonte Tardío, caracterizados por importantes contextos religiosos organizados en seges ${ }^{1}$, como los adoratorios del cuadrante Chinchaysuyo (Bauer, 2000)².

El área que ocupa el templo de Santa Ana, topográficamente notable sobre el resto de la ciudad (Figura 1), era una plataforma ceremonial o usnu ${ }^{3}$ que llevaba el nombre de Markatampu, lugar donde se practicaban rituales que incluían sacrificios humanos (Bauer, 2000). La erradicación de esta costumbre religiosa prehispánica quizás fue una de las razones por la cual en el siglo XVI se estableció allí el templo cristiano (Zecenarro, 2005). De igual modo, por este sitio también cruza hasta la actualidad el Camino inca a Chinchaysuyo; se trata de parte del Qhapaq Nan, camino que durante el periodo virreinal articuló la zona de Huancavelica -donde se extraía el mercurio- con los ricos yacimientos de plata de Potosí, en el Alto Perú. En dicha ruta, Cusco era un punto de paso muy destacado, económicamente privilegiado.

En 1562, siguiendo las disposiciones del virrey Andrés Hurtado de Mendoza, marqués de Cañete, el corregidor del Cusco Juan Polo Ondegardo instituyó al noroccidente de la ciudad la Parroquia de Indios de la Gloriosa Santa Ana, una de las cinco primeras parroquias establecidas en el Cusco ${ }^{4}$. En este entorno se consolidó la trama urbana de la parroquia, desplegada sobre las fuertes pendientes que caracterizan la topografía del lugar, trama cobijada bajo su principal edificio religioso (Vidal, 1958), levantado encima de la plataforma inca (Figura 2). Como se desprende de los documentos vinculados a la estancia del virrey Toledo, este contexto urbano albergó a los ayllus Qollana Wanka, Yanakuna, Kayau Qispiwara, Poroy y Chinchaysuyu (Amado, 2009), además de los Chachapoya y Kañari, afincados en el lugar, dotados de concesiones y privilegios por los españoles debido a los servicios prestados a la Corona en su lucha contra los incas.

Construido según los cánones del Renacimiento, estilo propio de las edificaciones religiosas de la segunda mitad del siglo XVI y primera mitad del XVII, cuando se consolidaban los procesos de colonización y evangelización, el templo de Santa Ana fue

\footnotetext{
1. Una forma de organización del territorio desde el punto de vista económico, social, político y religioso, los seqes eran rumbos o franjas territoriales que, a manera de líneas imaginarias que partían de un centro común -el templo del Qorikancha-, articulaban los distintos recursos naturales y/o elementos del paisaje considerados sagrados: las wakas. Cada seqe estaba a cargo de un grupo social de fuerte presencia política, que administraba y controlaba estos recursos, principalmente el agua.

2. La proyección de los seqes sobre el territorio cusqueño fragmentaba el espacio geográfico en 42 segmentos, que contenían alrededor de 350 adoratorios o wakas, organizados de acuerdo a los cuadrantes: Chincha (al noroccidente) y Anti (al nororiente) en la parcialidad de arriba o Hanansaya, y Qolla (suroriente) y Kunti (al suroccidente) en la parcialidad de Urinsaya, o abajo.

3. El usnu o chogepillaka era una estructura piramidal considerada sagrada que simbolizaba al propio dios Sol (Zecenarro, 2004).

4. Las primeras cinco primeras parroquias instituidas fueron San Cristóbal (Qollqanpata), San Blas (T'oqokachi), Santa Ana (Karmenqa), de los Reyes o parroquia de Belén (Kayaokachi), y los Mártires o parroquia de San Sebastián (Qollqapanpa) (Ángles, 1983). Posteriormente, ya en tiempos del virrey Francisco de Toledo, se sumarían a estas las parroquias de Santiago y San Jerónimo.
} 

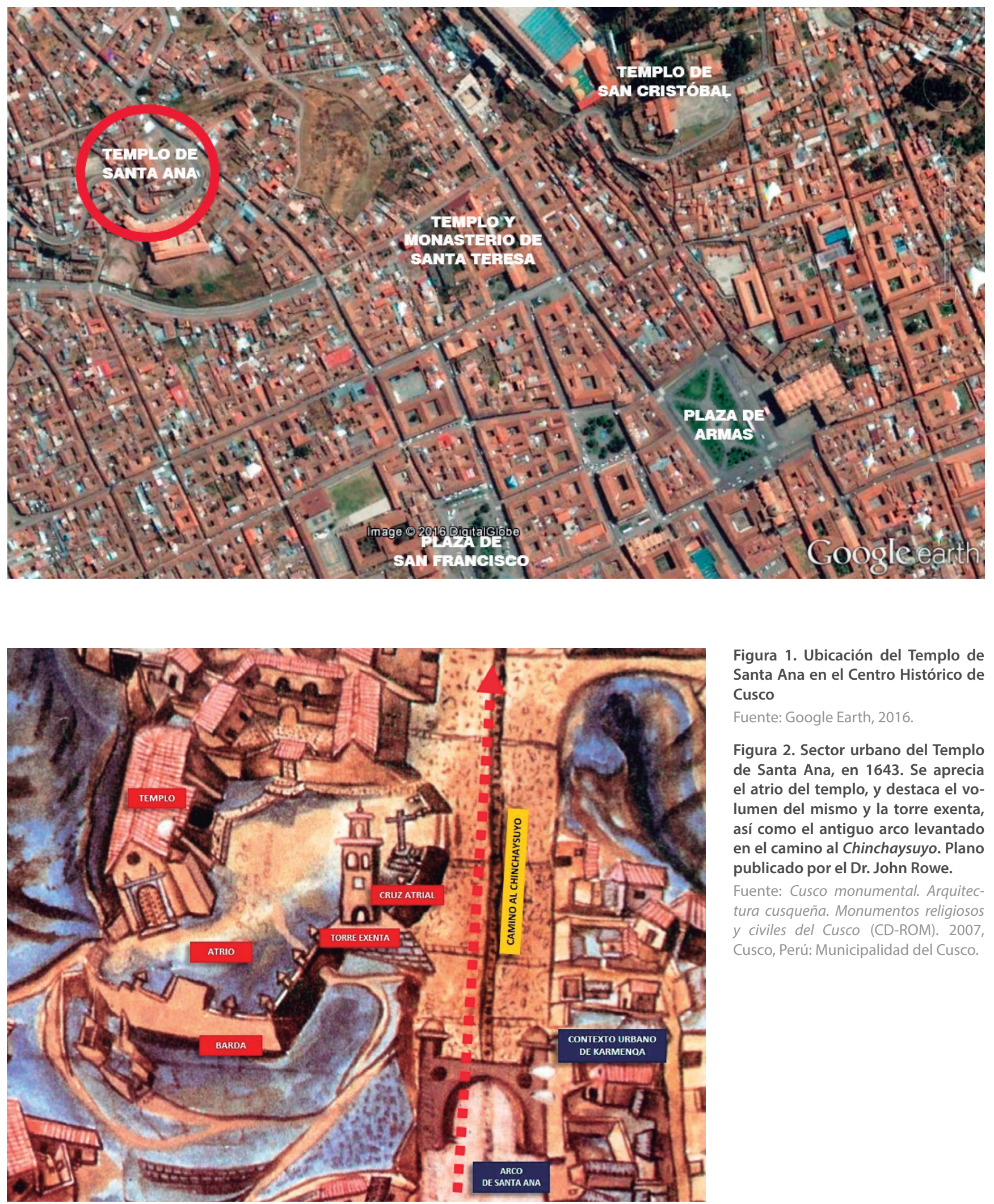

Figura 1. Ubicación del Templo de Santa Ana en el Centro Histórico de Cusco

Fuente: Google Earth, 2016.

Figura 2. Sector urbano del Templo de Santa Ana, en 1643. Se aprecia el atrio del templo, y destaca el volumen del mismo y la torre exenta, así como el antiguo arco levantado en el camino al Chinchaysuyo. Plano publicado por el Dr. John Rowe.

Fuente: Cusco monumental. Arquitectura cusqueña. Monumentos religiosos y civiles del Cusco (CD-ROM). 2007, Cusco, Perú: Municipalidad del Cusco. 


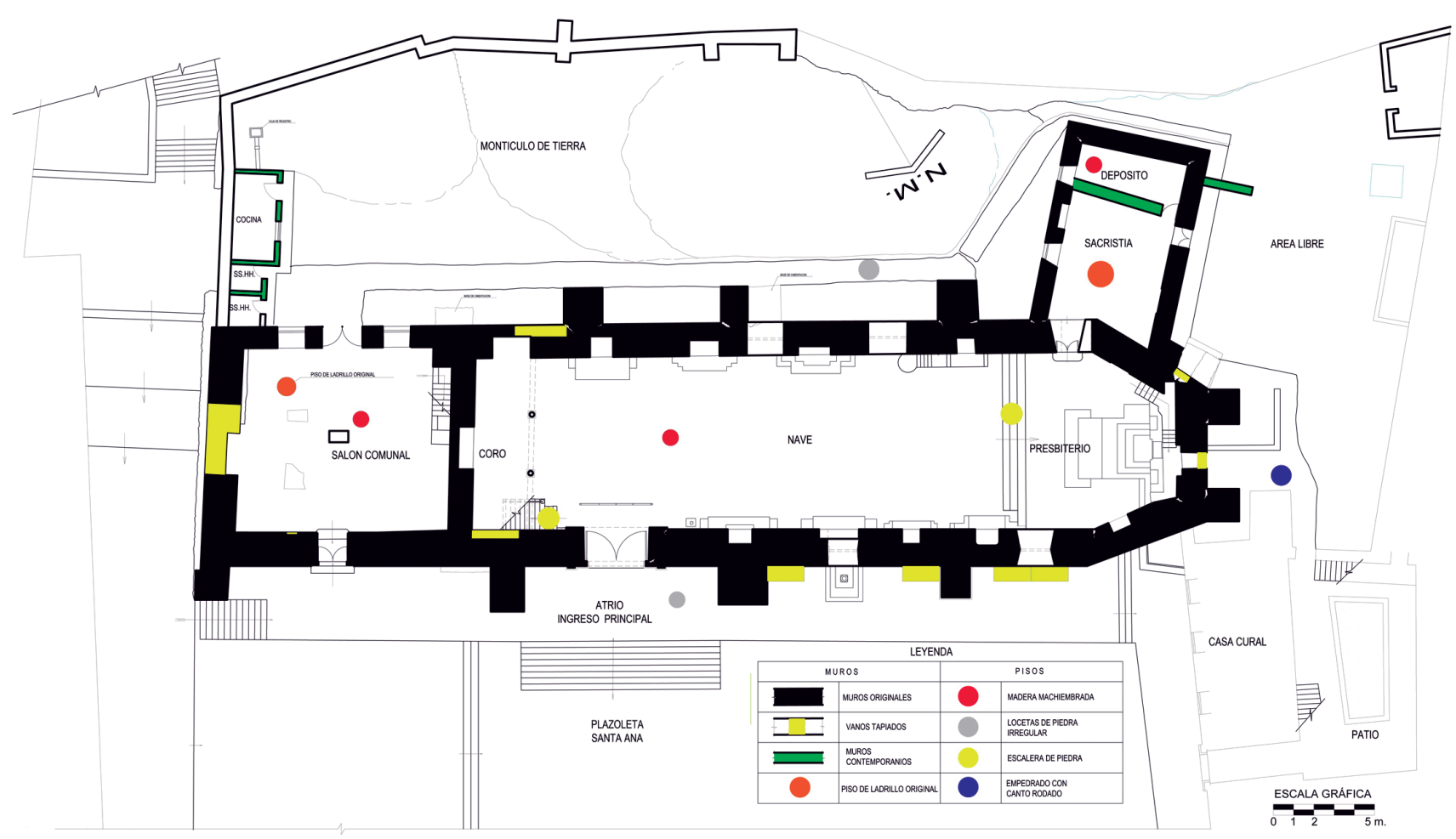

Figura 3. Planta del templo antes de la intervención

Fuente: Expediente técnico anual 2007. Restauración y puesta en valor del monumento histórico artístico Templo de Santa Ana - Cusco. 2007. Cusco, Perú: Dirección Regional de Cultura. edificado empleando adobe y piedra -material proveniente del desmontaje de las estructuras prehispánicas preexistentes-, y mano de obra aborigen. Esta acción constructiva cumplía también con los preceptos adoptados por los Concilios Limenses, que establecían la sustitución de los antiguos santuarios andinos, las wakas, por símbolos cristianos como una forma de erradicación de las idolatrías y fijación de la nueva religión sobre los cultos considerados paganos (Zecenarro, 2013b).

El edificio sufrió considerables daños como consecuencia del devastador sismo del jueves 31 de marzo de $1650^{5}$. La reconstrucción involucró su reparación, que mantuvo la concepción original de una sola nave. De proporciones alargadas, la nave del templo está definida por anchos y altos muros de adobe que hacia la cabeza configuran un ábside ochavado, casi puntiagudo. Como es propio de esta tipología, esta nave larga y estrecha -arriostrada por potentes contrafuertes- tenía en sus pies al sotocoro y coro sostenidos por arcos, sector que en el siglo XX sufrió un colapso (Guevara, 2007), lo cual tuvo como resultado el recorte de la nave debido a la construcción de un muro transversal a manera de pies, así como la adaptación de un nuevo coro en pleno espacio de la nave (Figura 3). De la misma forma, en los subsuelos de la nave se introdujo una cripta sepulcral, hallada gracias a los trabajos de exploración efectuados durante la restauración (Guevara, 2007).

Como es norma en este tipo de edificaciones religiosas, la nave está cubierta por una techumbre a dos aguas sostenida por armaduras de par y nudillo. La volumetría masiva del templo queda acentuada en el sector del presbiterio, acusado por su ábside ochavado. Según el diseño original, se accede al recinto religioso a través de una portada ubicada

5. Dos documentos gráficos de aquella época evidencian las características formales del templo de Santa Ana: el plano a la acuarela realizado en 1643, que muestra las parroquias de Santa Ana y de los Naturales (San Pedro), y el lienzo conocido como Panorama de Monroy, pintado en 1650, que muestra los daños causados por el terremoto. Actualmente este se conserva en la Catedral del Cusco. 


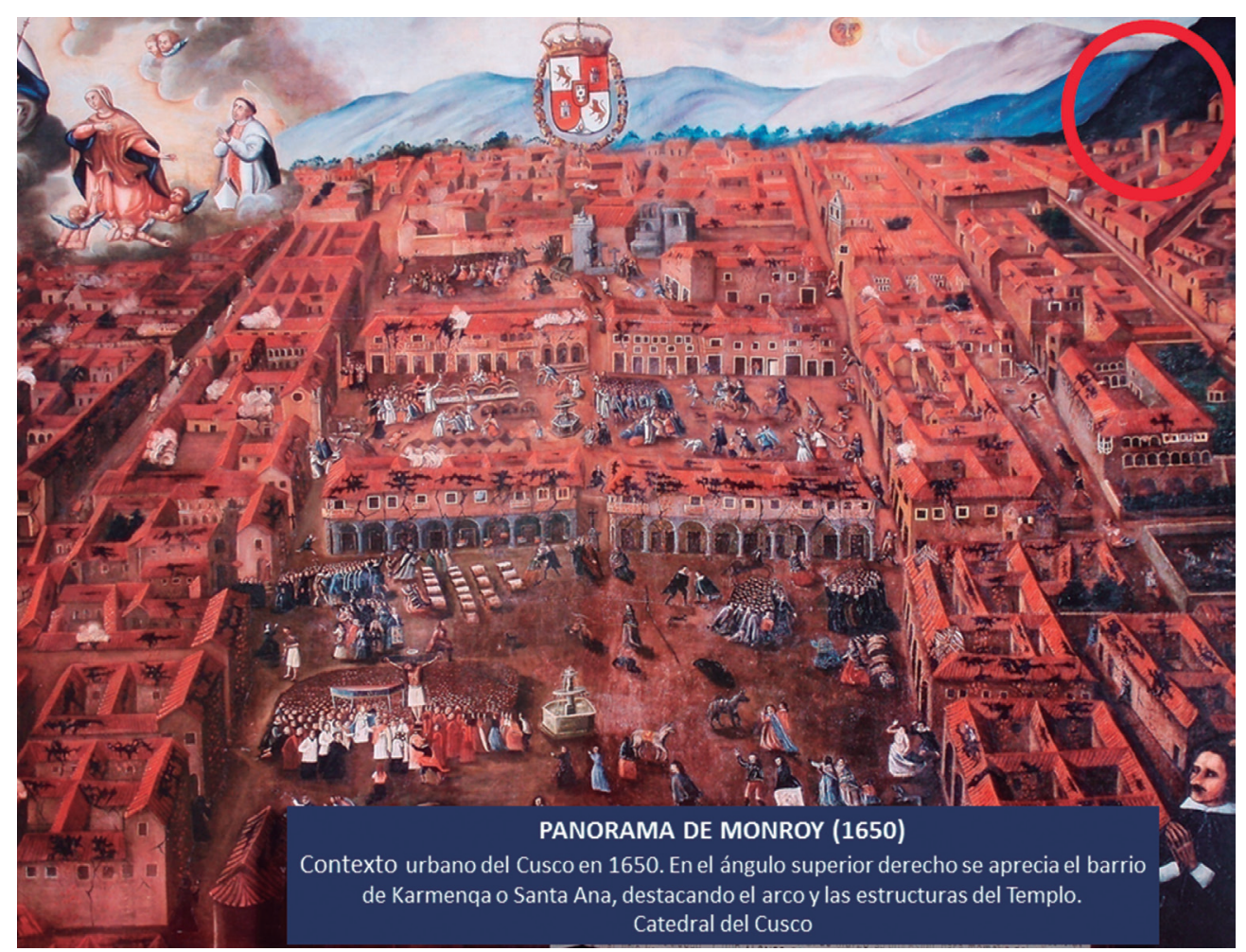

en el muro de pies, cuya evidencia gráfica está en el plano del Cusco de 1643 y en el Panorama de Monroy, de 1650 (Figura 4). Otro vano -de lenguaje manierista- fenestra el muro del lado de la Epístola, flanqueado por contrafuertes y rematado por un tejaroz.

Todo el conjunto queda enfatizado sobre el andén y la plataforma que le sirven de base, el cual por su morfología corresponde a la antigua Markatampu. No obstante, el elemento característico de las estructuras religiosas del periodo histórico al cual pertenece Santa Ana es el atrio, espacio con el cual la estructura del templo conformaba una unidad indisoluble; hoy, lamentablemente este está totalmente desvirtuado y desarticulado del templo, disuelto con el espacio urbano de la plaza y ocupado por una edificación de la segunda mitad del siglo XX (obra construida en 1984) (Figura 5). Propio de los tiempos tempranos de la Conquista, tanto en México como en Perú, el atrio forma parte de los elementos y espacios constitutivos que pertenecen a la arquitectura de la evangelización, los cuales conllevan un repertorio simbólico que enlaza lo cristiano con los rituales prehispánicos. Como una forma de exteriorizar el culto cristiano -haciéndolo semejante a los antiguos rituales-, en el siglo XVI se planteó la introducción de ciertos elementos arquitectónicos capaces de suplir las costumbres ancestrales, como las capillas abiertas o de indios, capillas miserere y absidales, los atrios y sus cruces atriales: todo un repertorio de nuevos elementos arquitectónicos que se introducen en la arquitectura religiosa americana (Mesa \& Gisbert, 2002).

En el caso del templo de Santa Ana, destaca la capilla absidal ubicada en el sector del ábside -evidenciada en 2007 junto con fragmentos de pintura mural-, y el significativo espacio que correspondía al atrio del templo, situado delante del muro de pies que ocupa la plataforma que hoy contiene a la plazoleta. Sin la presencia del atrio, sería incomprensible y parcial la interpretación arquitectónica integral de cualquier recinto religioso de esa época (Zecenarro, 2013b), argumento que lamentablemente el proyecto de restauración integral no consideró, como se analiza más adelante.
Figura 4. Panorama de Monroy (detalle). El Barrio de Karmenqa o Santa Ana, parte del tejido urbano de Cusco, s. XVII. Lienzo pintado después del terremoto del 31 de marzo de 1650

Fuente: Fotografía por Zecenarro Benavente, 2016. 


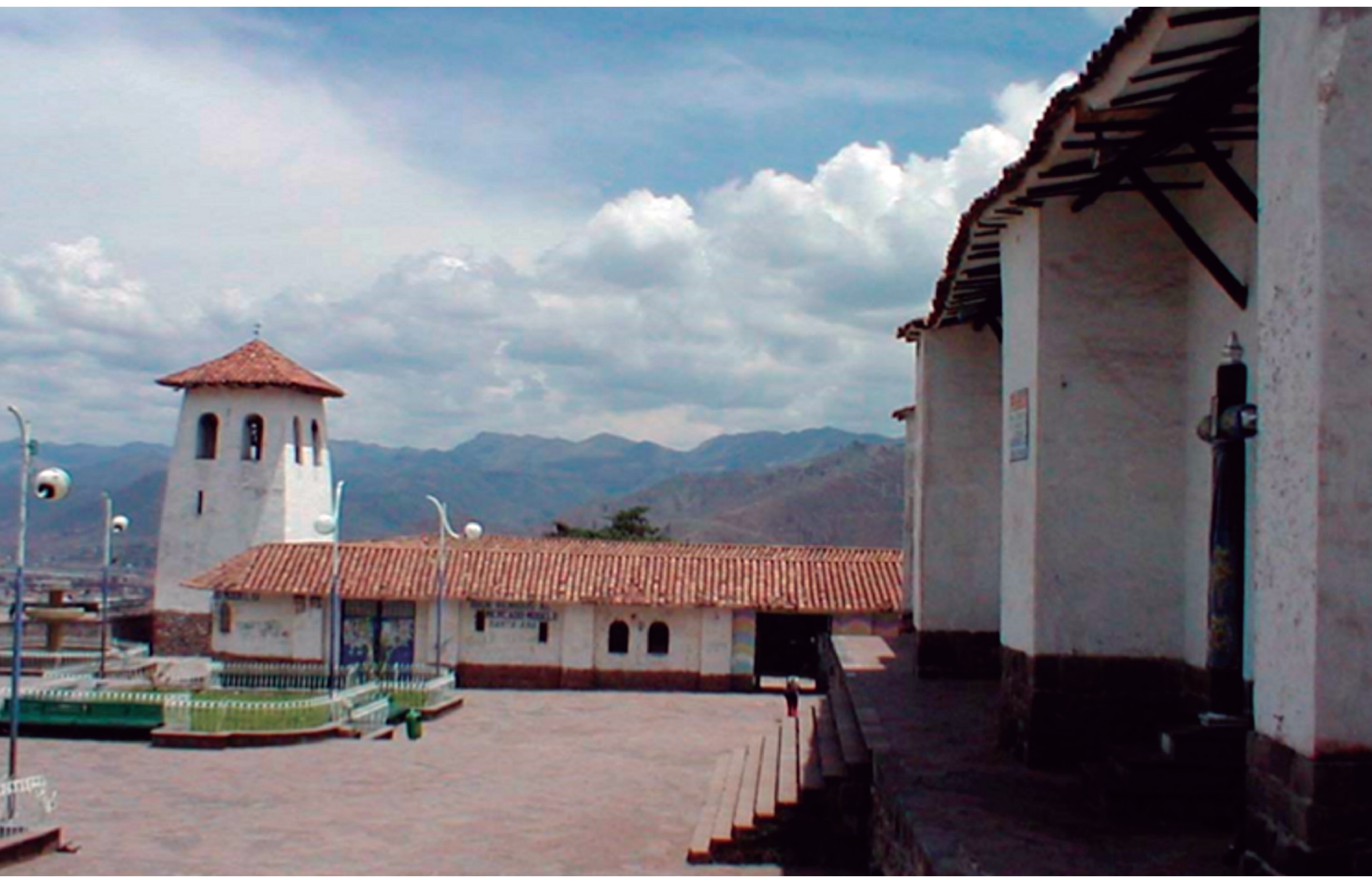

Figura 5. Conjunto urbano monumental de Santa Ana, 2004. Se aprecia la torre exenta y el bloque construido sobre el espacio del atrio Fuente: Cusco monumental. Arquitectura cusqueña. Monumentos religiosos y civiles del Cusco (CD-ROM). 2007, Cusco, Perú: Municipalidad del Cusco.
Construida en sitio expectante de la plazoleta, se alza de forma exenta una torre campanario de planta cuadrangular, también fabricada en adobe, con cobertura de tejas cerámicas. Reconstruida por la Corporación de Reconstrucción y Fomento del Cusco (CRIF) después del terremoto de 1950, lo cual implicó una serie de cambios tanto en sus proporciones como en su morfología, esta torre -no incluida en el proyecto de restauración del templo en el año 2006- se alza aún dominante sobre la plazoleta, a manera de atalaya sobre toda la ciudad (Figura 6).

En el interior del templo, en marcado contraste con la austera y sencilla arquitectura, la nave se decoró en tiempos coloniales con una serie de cuadros al óleo, marquetería y esculturas de gran valor artístico y documental (Benavente, 1995). Destaca la serie de lienzos de formato grande -datados hacia finales del siglo XVII- que representa la festividad del Corpus Christi, hoy en custodia en el Museo de Arte Religioso del Arzobispado del Cusco (Villanueva, 1989; Vidal, 1958). Además, enaltecen la riqueza artística del templo un grupo de esculturas realizadas por Juan Tomás Tuyru Tupaq Inca, "Sargento Mayor de los Nobles Incas"; entre ellas resaltan las puertas policromadas del tabernáculo del desaparecido retablo mayor, el Santo Cristo de la Agonía o de las Ánimas, un San Jerónimo penitente y la imagen patronal de Santa Ana, obras realizadas en 1679 (Benavente, 2006). En cuanto a los retablos, después del sismo de 1650, el templo probablemente se decoró con una serie de retablos de 


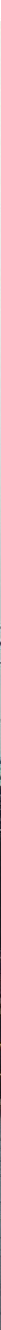

corte barroco, realizados en madera de cedro y acabados con pan de oro, acordes al estilo imperante en aquella época. Posteriormente, al imponerse el estilo neoclásico, estos lamentablemente fueron desmontados, y quedaron únicamente piezas dispersas que fueron ubicadas durante trabajos de intervención recientes.

\section{La intervención arquitectónica del templo}

La calidad e importancia de los monumentos patrimoniales existentes en la ciudad y en la región geográfica que corresponde al departamento del Cusco motivaron desde muy temprano el interés en cuanto a su conservación, pues se les considera elementos icónicos del Perú y América. Los trabajos pioneros efectuados con motivo del cuarto centenario de la fundación española del Cusco, en 1934, comprometieron un considerable presupuesto extraído del erario nacional, destinado a afrontar las intervenciones que se realizarían en los principales conjuntos arqueológicos y edificaciones virreinales de la ciudad, que entonces comenzaba a surgir como capital arqueológica de América. Por esta razón, después del sismo de 1950, se consideró como prioridad la restauración y recuperación de la ciudad, proceso que se encomendó a equipos profesionales que realizaron ponderada labor -caso de la CRIF-, esta vez con el objetivo de activar una dinámica económica basada en la industria turística.
Figura 6. Torre exenta de Santa Ana Fuente: Fotografía por Zecenarro Benavente, 2016. 
Figura 7. Finalidad de la crítica a la restauración en arquitectura Fuente: Elaboración propia, 2017.

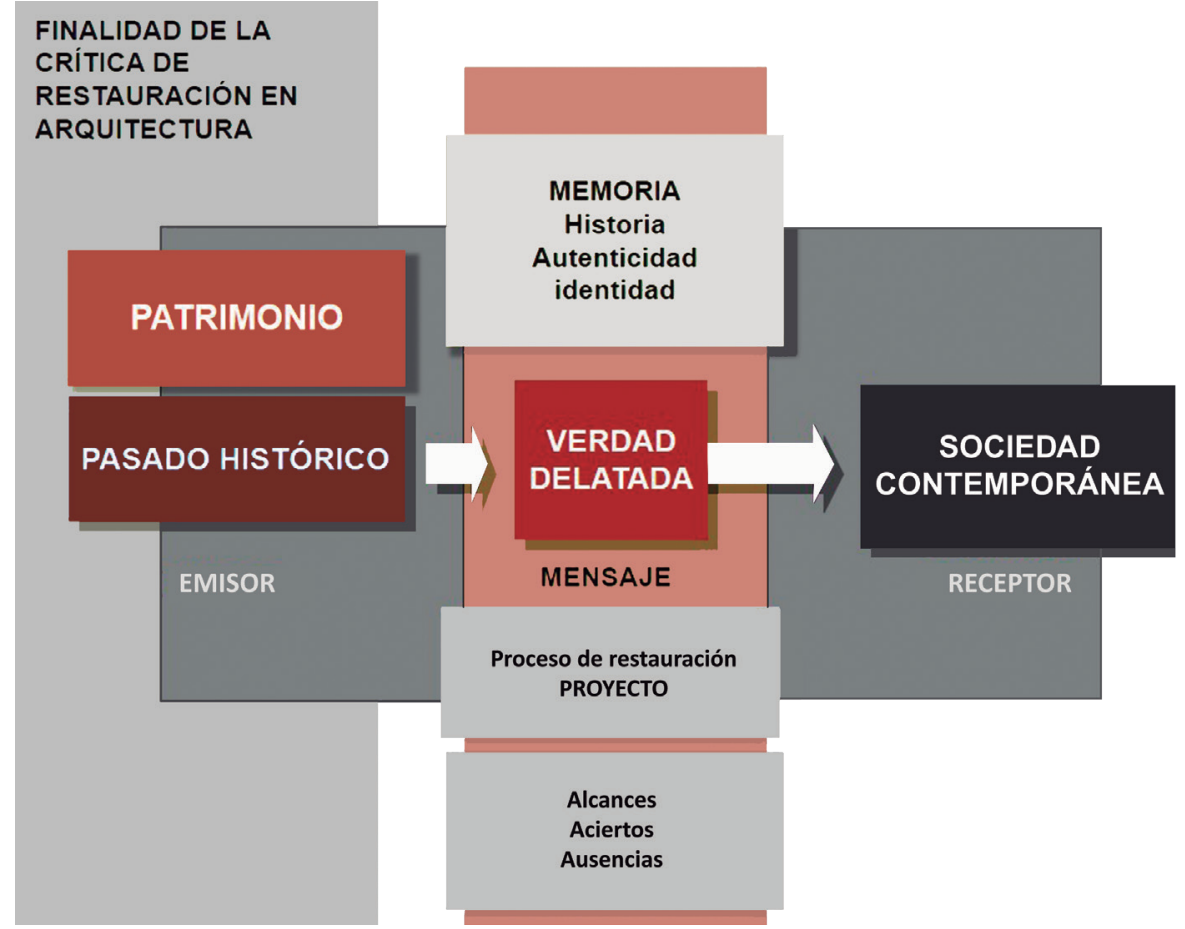

Continuando estas acciones, los proyectos PER 39 y el Plan COPESCO lideraron una serie de programas de desarrollo basados en la recuperación integral y puesta en valor de monumentos, principalmente en el eje Cusco-Puno. En 1972 el Estado peruano, a través del Instituto Nacional de Cultura, se hizo cargo de las acciones de conservación y mantenimiento de los monumentos de la ciudad, los cuales ya habían cobrado singular interés a nivel mundial, hecho que se puntualizó con el reconocimiento de UNESCO y la declaratoria de Cusco como Patrimonio Cultural de la Humanidad en 1983.

Tras estos alcances, como parte de los programas de intervención de los monumentos del Cusco, los objetivos planteados en el expediente técnico de restauración y puesta en valor del templo de Santa Ana-ejecutados en el periodo 2006-2012 por la entidad gubernamental-forman parte de una serie de procesos metodológicos orientados a recuperar de manera integral el monumento, que incluían trabajos en arqueología, arquitectura y bienes muebles. Las intervenciones en Santa Ana iniciaron en 2006, como parte de los proyectos de conservación y restauración del patrimonio religioso inmueble de la región del Cusco, a cargo de la Dirección de Conservación del Patrimonio Cultural Inmueble - Sub Dirección de Obras, del Instituto Nacional de Cultura -hoy Ministerio de Cultura-, Dirección Desconcentrada de Cultura Cusco (Guevara, 2007).

Al tener a la sociedad contemporánea como receptor, todo hecho arquitectónico transmite o delata -en tanto mensaje-, una verdad o memoria que debe develarse e interpretarse en función a un análisis histórico y crítico que depende fundamentalmente de la autenticidad que conservan sus elementos físicos, es decir, la naturaleza de su materialidad a través del tiempo (Chanfón, 1983) (Figura 7). Con la intención de conservar los elementos constitutivos del edificio, surgen en la práctica de la conservación una serie de planteamientos metodológicos orientados a la recuperación integral de las edificaciones históricas a través de proyectos de intervención y ejecución de obra. En forma paralela, también está presente el análisis crítico a estos procesos, el cual tiende a ponderar los alcances de la propia intervención, así como sus omisiones (Montaner, 2002), con el fin de convertirse en herramienta que permita dilucidar y jus- 

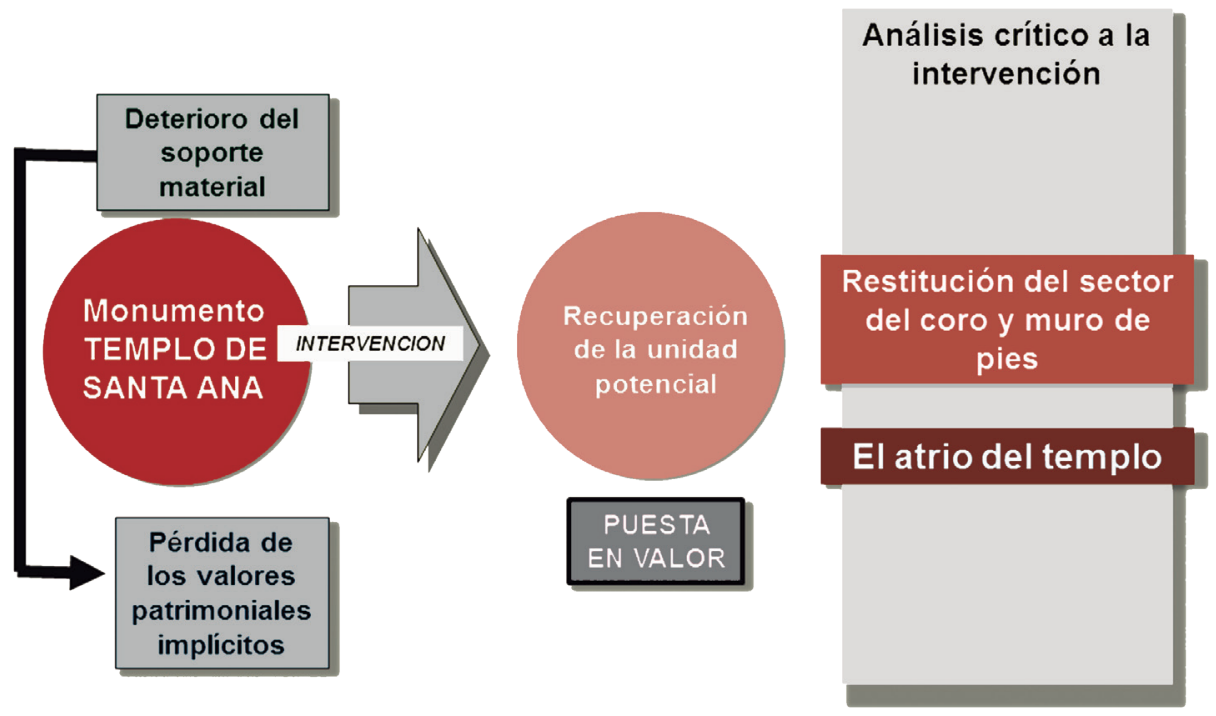

Figura 8. Objetivo de la restauración arquitectónica del Templo de Santa Ana

Fuente: Elaboración propia, 2017.

Figura 9. Planta de propuesta de restauración en el Templo de Santa Ana Fuente: Expediente técnico anual 2007. Restauración y puesta en valor del monumento histórico artístico Templo de Santa Ana - Cusco. 2007. Cusco, Perú Dirección Regional de Cultura..

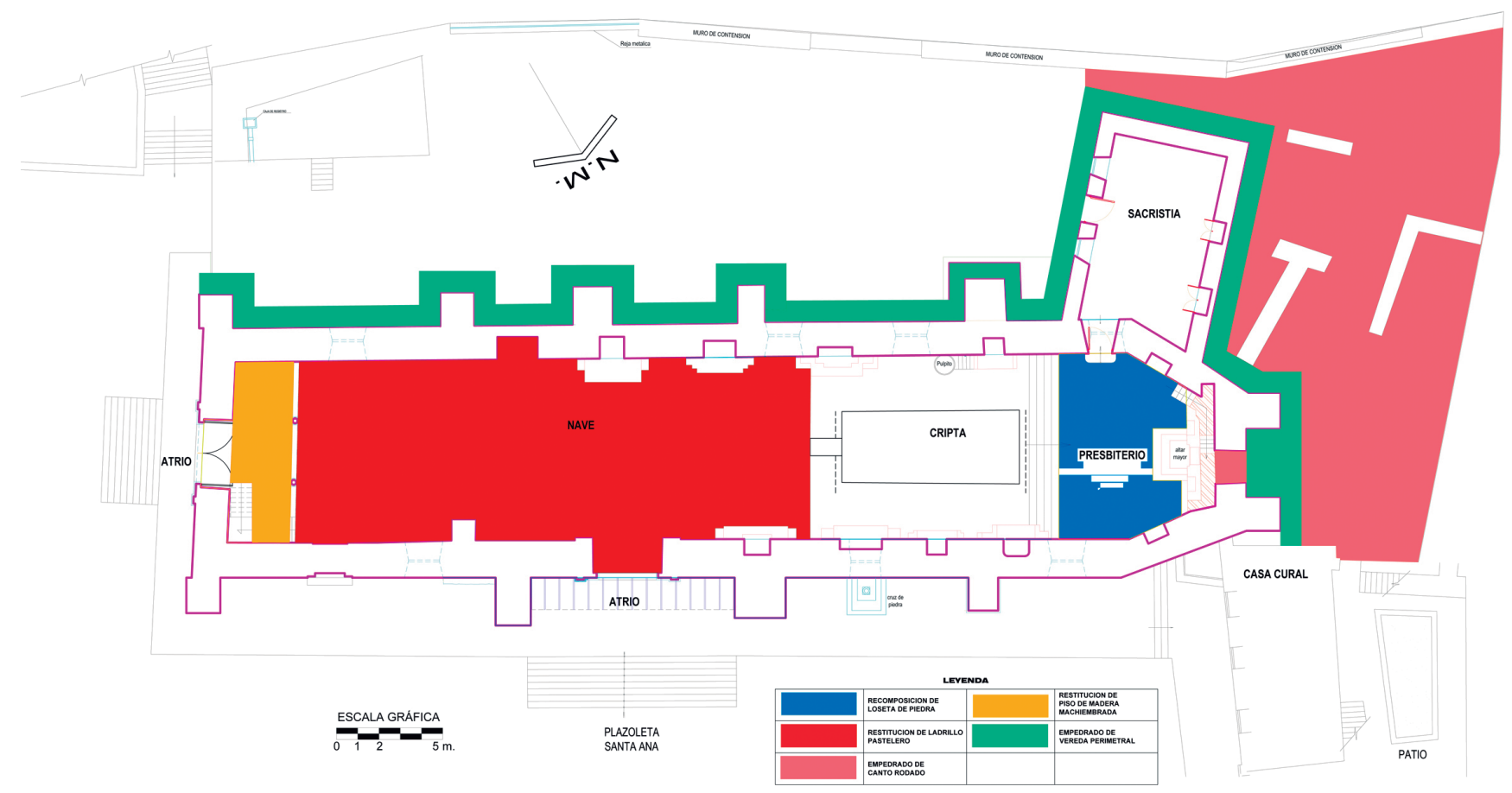


devenir VOL. 4, Nº7, ENERO - JUNIO 2017, PP. 117-144 - ESTUDIOS | ISSN 2312-7562

UNIVERSIDAD NACIONAL DE INGENIERÍA, LIMA

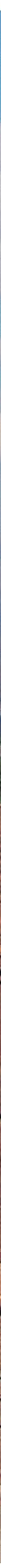

Figura 10. Estado del Templo de Santa Ana en el contexto del barrio de Karmenqa, durante la intervención Fuente: Fotografía por Guevara Boza, 2007. Ministerio de Cultura. tificar similares en el campo de la conservación y restauración patrimonial. En el caso del Cusco, esta práctica ha marcado historia desde la década de los años 50, época en que la gestión gubernamental y la comunidad internacional fomentaron la recuperación de sus principales testimonios monumentales (Figura 8).

El planteamiento de los trabajos exploratorios programados en Santa Ana permitió el acercamiento a las características físicas del edificio y de todos sus elementos constitutivos, a fin de develar los valores intrínsecos del monumento y todos los factores que ponían en riesgo su integridad. De la misma forma, el proyecto de intervención 2006-2012 contempló acciones de liberación de elementos añadidos y de todos aquellos que desvirtuaron, en algún momento de su historia, la concepción original del edificio (Figura 9). 
La historia del monumento permitió evidenciar en varias oportunidades problemas estructurales. Uno de ellos data de 1910 y, según la breve referencia registrada, su magnitud involucró la reconstrucción de importantes sectores del templo desde la cimentación (Guevara, 2007). En muchos casos las patologías que se manifestaron se debían a la presencia de focos de humedad, provenientes de las edificaciones vecinas, y ocasionados por las malas condiciones de las coberturas y sistemas de evacuación del agua pluvial, que en tiempo de lluvias colapsaron. En otros casos los daños se debieron al comportamiento de los elementos del templo ante eventos sísmicos (Figura 10).

Por ello, los trabajos de intervención apuntaron a la consolidación de las estructuras de cimentación y muros de carga, a fin de conservar el componente material del monumento en sus mejores condiciones estáticas. Se realizaron trabajos de calzadura de cimientos y sobrecimientos, complementados con obras de drenaje y conducción de agua. Se practicaron costuras en muros, además de la inclusión de llaves de madera como refuerzo estructural en los encuentros. La exploración arqueológica determinó también la existencia de contrafuertes y elementos de arriostre en los exteriores de la nave, datos importantes que posibilitaron su atención y oportuna inclusión en el plan de consolidación estructural del monumento.

Durante los trabajos exploratorios y de liberación, se hallaron materiales de construcción y elementos arquitectónicos provenientes de la obra original, los cuales sirvieron de modelo para las restituciones correspondientes. Estos materiales fueron registrados y debidamente almacenados, con el objetivo de plantear una exposición permanente in situ como parte de la historia constructiva del monumento.

Los datos de José María Blanco en el famoso diario del viaje del presidente Orbegoso al sur del Perú (Blanco, 1974) señalan que en 1836 los pisos de la nave eran simplemente de tierra apisonada. Blanco no registró losetas de piedra o argamasa ${ }^{6}$, ni mucho menos ladrillos pasteleros, que sí aparecen en edificaciones similares; posiblemente las condiciones de mantenimiento inadecuado o el estado de abandono a través del tiempo ocasionaron que estos elementos desaparezcan. Bajo el razonamiento de que todos los edificios de esta tipología llevaban ese material de acabado, se decidió utilizarlo en los pisos de la nave, respondiendo a los criterios de la restauración estilística, denotando un estado completo que, en términos de Viollet-le-Duc, quizás no haya existido nunca (González-Varas, 2008).

De la misma forma, el tratamiento del portón principal se realizó mediante injertos y composturas de sus elementos, a fin de recuperar la imagen integral del elemento, en la cual jugaban un papel importante las bulas de bronce. Tomando en cuenta sus características, se restauraron varias de estas cabezas de clavos, y se reconstruyeron otras, muy similares a las originales, según el criterio estilístico. Hubiera sido interesante considerar alguna muesca o marca que permita la diferenciación de estos elementos nuevos, de acuerdo con las recomendaciones del postulado décimo segundo de la Carta de Venecia, en el cual se explicita la necesidad de diferenciar las partes añadidas de los elementos originales para evitar falsificaciones (Instituto Nacional de Cultura, 1989).

Durante los trabajos de exploración realizados en 2007, el arqueólogo Reynaldo Bustinza ubicó una cripta debajo de la nave del templo (Guevara, 2007). Por sus características constructivas, este elemento posiblemente corresponde a la segunda mitad del siglo XVII. Construidas en un sitio jerárquico, debajo y adyacente al presbiterio, el fin de estas cámaras subterráneas fue servir de cementerio (osario) a personas pudientes, quizás generosos donantes o benefactores indígenas del templo o la parroquia. El proyecto incluyó su puesta en valor.

6. Mortero constituido por una mezcla de cal, arena y ceniza 
devenir VOL. 4, Nº7, ENERO - JUNIO 2017, PP. 117-144 - EsTUDIOS I ISSN 2312-7562

UNIVERSIDAD NACIONAL DE INGENIERÍA, LIMA

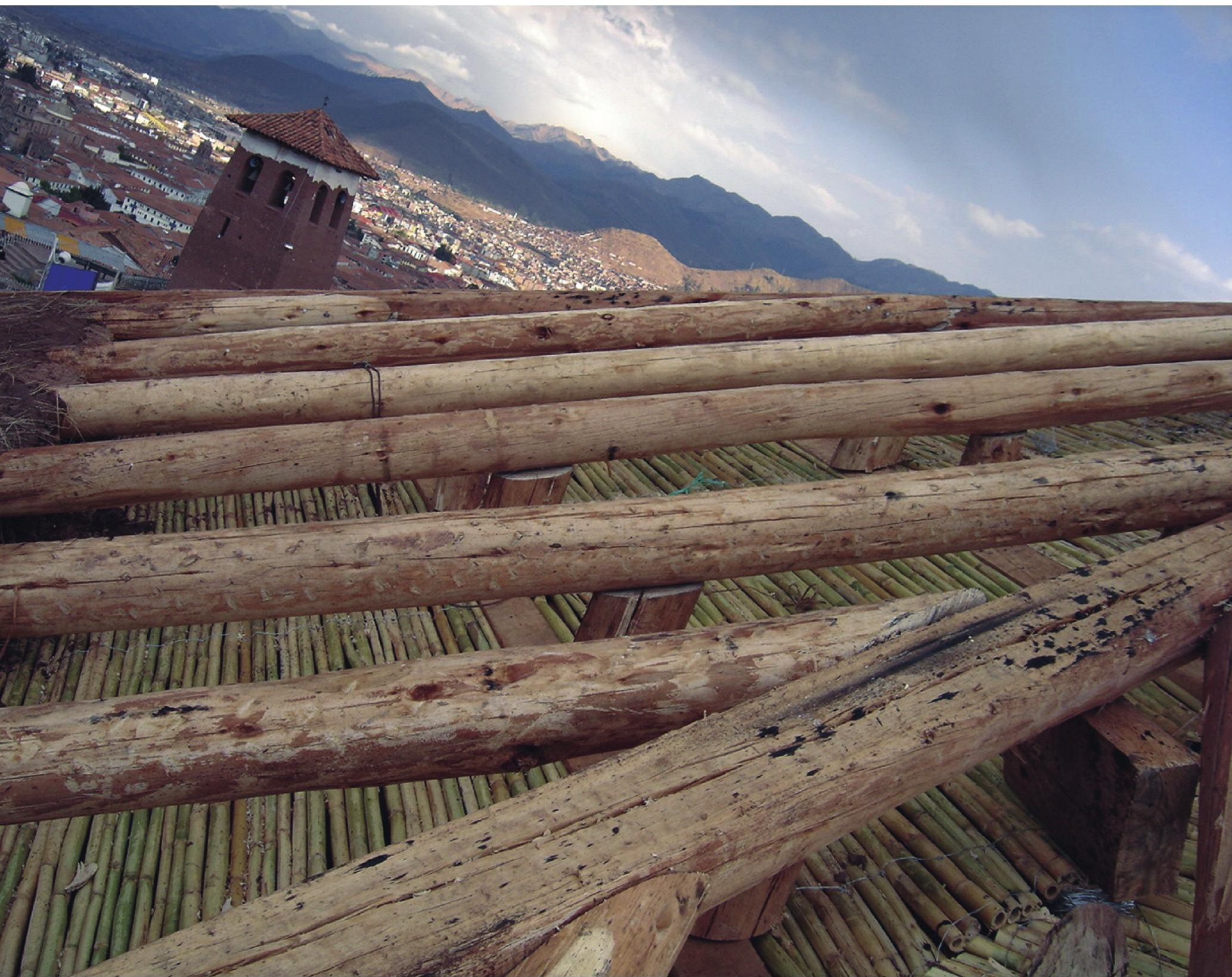

Figura 11. Restitución de las coberturas de par y nudillo

Fuente: Fotografía por Quispe Ricalde, 2009.
Se desconocen las características constructivas de la cobertura original del templo. Solamente siguiendo criterios históricos y estilísticos se puede plantear que se trató de una estructura de par y nudillo, encima de la cual se colocaba un encañado utilizando el kurkur traído de las selvas cusqueñas. Sobre este se disponía una torta de barro y luego se colocaban tejas cerámicas, cuyas formas y dimensiones se conocen objetivamente gracias a ejemplares recuperados durante las exploraciones.

Existe documentación que prueba los diferentes cambios que sufrió la cobertura debido a procesos de mantenimiento, como las reparaciones llevadas a cabo entre 1944 y 1945 (Guevara, 2007). Debido a su avanzado estado de deterioro, el proyecto de 2006 consideró una intervención integral, y se sustituyó toda la cubierta en 2010 (Guevara, 2007), de acuerdo al criterio formal estilístico (Figura 11), que se sigue en todos los 


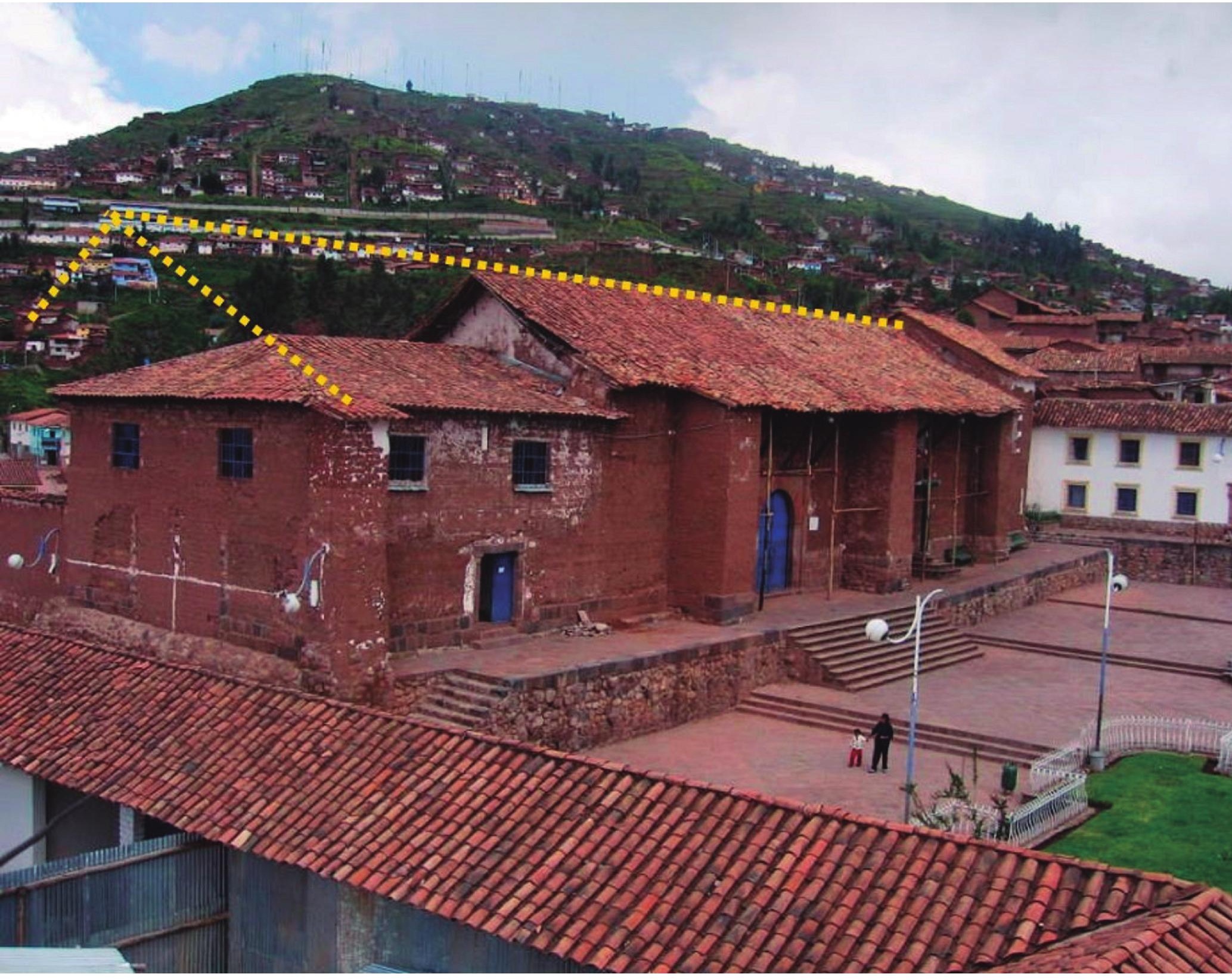

procesos de restauración de inmuebles históricos en el ámbito, con el fin de recuperar el "estado completo" de la obra (González-Varas, 2008, p. 159).

En cuanto al caso de la torre exenta, sobre esta se posee un testimonio gráfico de 1643; como se desprende de la lectura del Panorama de Monroy, este elemento sucumbiría con el sismo de 1650. Al siglo XX llegaría una torre construida en el mismo lugar que la precedente, pero con características muy distintas a la original, que fuera demolida y reconstruida como parte de las obras emprendidas por la Junta de Reconstrucción y Fomento Industrial del Cusco entre 1951 y 1956. Esta reconstrucción no tomó en cuenta los testimonios documentales ni la forma de la antigua torre caída en 1950, por lo que se considera un falso histórico, el cual no guarda relación con testimonios que podrían haber justificado una intervención histórico-analítica.
Figura 12. Templo de Santa Ana durante la Intervención. Se aprecia el sector del coro a restituir.

Fuente: Fotografía por Guevara Boza, 2007. Ministerio de Cultura. 
devenir VOL. 4, Nº7, ENERO - JUNIO 2017, PP. 117-144 - EsTUDIOS I ISSN 2312-7562

UNIVERSIDAD NACIONAL DE INGENIERÍA, LIMA

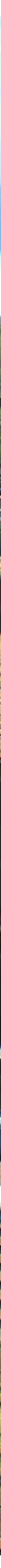

Figura 13. Vista del sector del muro de pies. Se observan los trabajos de reconstrucción del coro y sotocoro, y la portada de pies.

Fuente: Fotografía por Guevara Boza, 2007. Ministerio de Cultura.

\section{La restitución del sector del coro y el muro de pies}

Se tiene conocimiento de que en marzo de 1910 el templo colapsó como consecuencia de un periodo climático muy lluvioso. No se cuenta con precisiones sobre las zonas o elementos afectados, pero posiblemente se derrumbó un sector importante de la estructura ${ }^{7}$, quizás el que correspondió al coro y el muro de pies. Se podría suponer entonces aquella fecha como el momento en que la nave sufre el recorte de su espacio, seguido de la construcción de un muro transversal que generó un recinto trasero de dos niveles, el cual fue utilizado como salón comunal desde aquella oportunidad (Figura 12).

7. El informe de la Oficina de Estudios y Proyectos del INC, a cargo de la Arq. Clara Luz Molina del Castillo, indica que por esta razón el templo tuvo que ser reconstruido desde sus cimientos (citada en Guevara, 2007). 


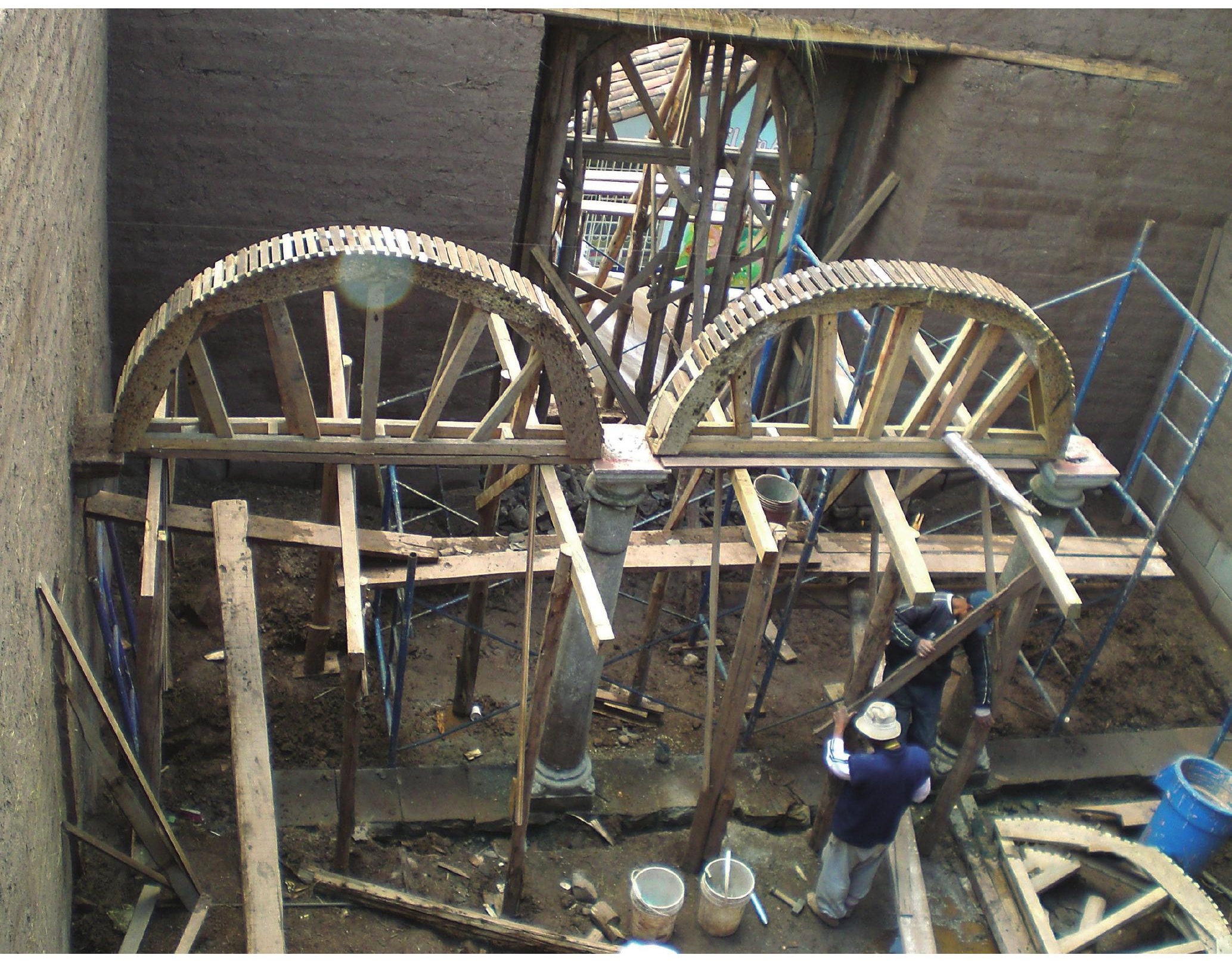

El proyecto de intervención planteado en 2006 consideró prioritario recuperar el espacio perdido de la nave (Figura 13). Para ello, se debían estudiar todos los vestigios y la documentación posible (Guevara, 2007), a fin de obtener un resultado debidamente justificado. Por lo tanto, el mismo año se realizaron exploraciones arqueológicas en el sector del salón comunal, que evidenciaron las bases del sistema de arcos que sostenía el primitivo coro del templo (Figura 14). Asimismo, la portada de pies fue reintegrada gracias a vestigios arqueológicos encontrados, testimonios iconográficos y analogías con otros edificios similares, como Oropesa, Huaro o San Jerónimo, entre muchos otros ejemplos (Zecenarro, 2013b).

Considerando solamente este aspecto, la intervención podría definirse como una restauración estilística (González-Varas, 2008), pero a ello se sumaron documentos, tanto gráficos como arqueológicos, que permitieron corroborar irrefutablemente la forma,
Figura 14. Reconstrucción del sector del coro y muro de pies. Cimbrado de los arcos del sotocoro

Fuente: Fotografía por Guevara Boza, 2007. Ministerio de Cultura. 
Figura 15. Vista interior de la nave del Templo de Santa Ana, hacia el muro testero y Altar mayor, 2013 Fuente: Fotografía por Seminario Solaligue, 2013.

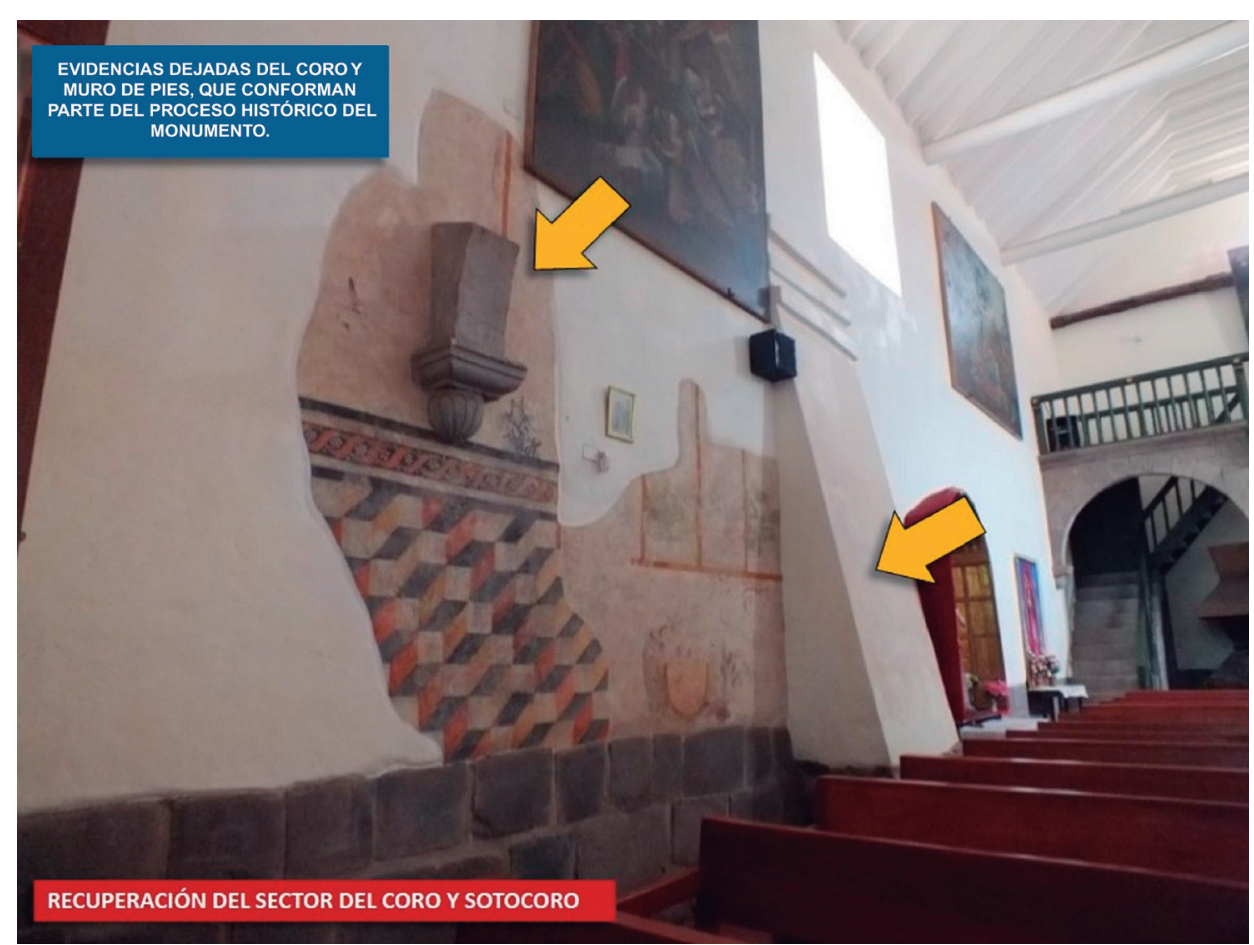

dimensiones e incluso las características del sector de pies de la nave. Por ello, partiendo del respeto de los valores históricos del monumento, con el aval de la investigación histórica, se admitió la legitimidad de la intervención bajo los principios de la restauración crítica, ya que el objetivo perseguido era el reconocimiento crítico de la obra, muy por encima de sus valores históricos y documentales. Se estaba buscando la integridad arquitectónico-figurativa del templo en cuanto a su forma original, volumetría y carácter renacentista del diseño, lo que Cesare Brandi (1977) denomina la recuperación de la unidad potencial de la obra de arte.

Sin embargo, es necesario comentar los detalles arquitectónicos que se han introducido en el espacio recuperado (Figura 15). Pese a que la restauración crítica tiene como principio el respeto absoluto al monumento y a sus distintas fases constructivas o estilísticas, existe también la obligatoriedad de que sea sencillo distinguir los añadidos introducidos en el mismo de las piezas originales -como se recomienda en la Carta de Venecia (Instituto Nacional de Cultura, 1989)-. En el caso del fragmento reconstruido, por la semejanza formal a sus elementos constitutivos, no es muy fácil distinguirlo del resto de la nave, excepto por la presencia de ciertas evidencias que se dejaron ex profeso a fin de permitir la lectura interpretativa de este momento de la historia del edificio (Figura 16).

Quizás hubiera sido plausible manifestar el sector reconstruido mediante un manejo distinto de materiales o formas arquitectónicas, como evidencia de una intervención contemporánea que contraste notoriamente con la obra original. Sin embargo, para recordar el momento histórico del recorte de la nave y la presencia de un nuevo coro dentro del espacio de la misma -hechos que ya forman parte de la historia del monumento-, el proyecto dejó a la vista fragmentos de este elemento: un pedazo del muro liberado -acondicionado como si fuera un contrafuerte inclinado-, que junto a un sotabanco y al salmer del primer arco señalan virtualmente el espacio acondicionado después del colapso del coro original (Figura 17). 


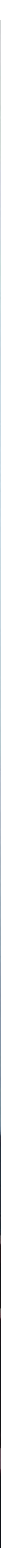

En el sotocoro destaca y contrasta, por su atipicidad, la circulación vertical construida para articular este espacio con el coro: una escalera acabada en piedra y sostenida por una bóveda en tranquil o rampante, elemento que aparece de manera intrusiva y entorpece la espacialidad. Por otro lado, el tratamiento de la portada de pies asume elementos que estilísticamente corresponden a la portada lateral, incluidas las bulas de bronce (Guevara, 2007); esta intervención sí puede calificarse como basada en la noción de reconstrucción estilística.

En cuanto al aspecto exterior, la reconstrucción de este sector ha posibilitado la recuperación de la volumetría original del templo. Al prolongar las caídas de la cobertura a dos aguas, se ha formado un nuevo hastial cuya silueta destaca, acusando la forma renacentista del edificio. En este caso, este detalle ha tomado como referencia la iconografía existente, tanto el plano de 1643 como el Panorama de Monroy de la Catedral del Cusco de 1650. La documentación de referencia que ha sido utilizada para este proceso permitió establecer el criterio de la restauración histórico-analítica (Figura 18).
Figura 16. Muro de pies, coro y sotocoro restituidos, con evidencias que expresan el proceso histórico constructivo

Fuente: Fotografía por Zecenarro Benavente, 2016. 
Figura 17. Vista interior de la nave del Templo de Santa Ana, hacia el sector del coro restituido

Fuente: Fotografía por Seminario Solaligue, 2013.

\section{El atrio del templo de Santa Ana}

En el marco de la gestión y los alcances técnicos que conlleva la acción restaurativa, se incide en este punto en un aspecto no contemplado en la propuesta arquitectónica, la articulación del proyecto de restauración y puesta en valor del templo con los proyectos de rehabilitación o remodelación del contexto urbano adyacente al mismo (Figura 19). Como se indica en la Carta de Venecia, el monumento es inseparable de su historia y del ambiente en el cual se emplaza (Instituto Nacional de Cultura, 1989); en ese sentido, el caso del atrio del templo de Santa Ana constituye una grave omisión en el proyecto. No se formularon pautas sobre este desaparecido espacio, lo cual hubiera sido valioso para articular la recuperación integral del monumento religioso con los proyectos de rehabilitación de la plaza de Santa Ana, obra que la autoridad municipal inició en el año 2016.

Como se ha señalado, el templo de Santa Ana se construyó sobre el adoratorio de Markatampu, una plataforma ceremonial o usnu (pirámide trunca) de carácter religioso (Zecenarro, 2004). Su configuración volumétrica fue propicia para superponer el templo cristiano con todas sus partes, denotando la correspondiente jerarquía sobre los espacios libres adyacentes y connotando la prerrogativa de la religión cristiana sobre los cultos andinos. Sacando provecho a la configuración arquitectónica de la plataforma ceremonial, se emplazaron las estructuras renacentistas del templo junto con el típico espacio abierto denominado atrio, común denominador en la arquitectura de la evangelización en México y Perú. Espacio característico de las tempranas estructuras

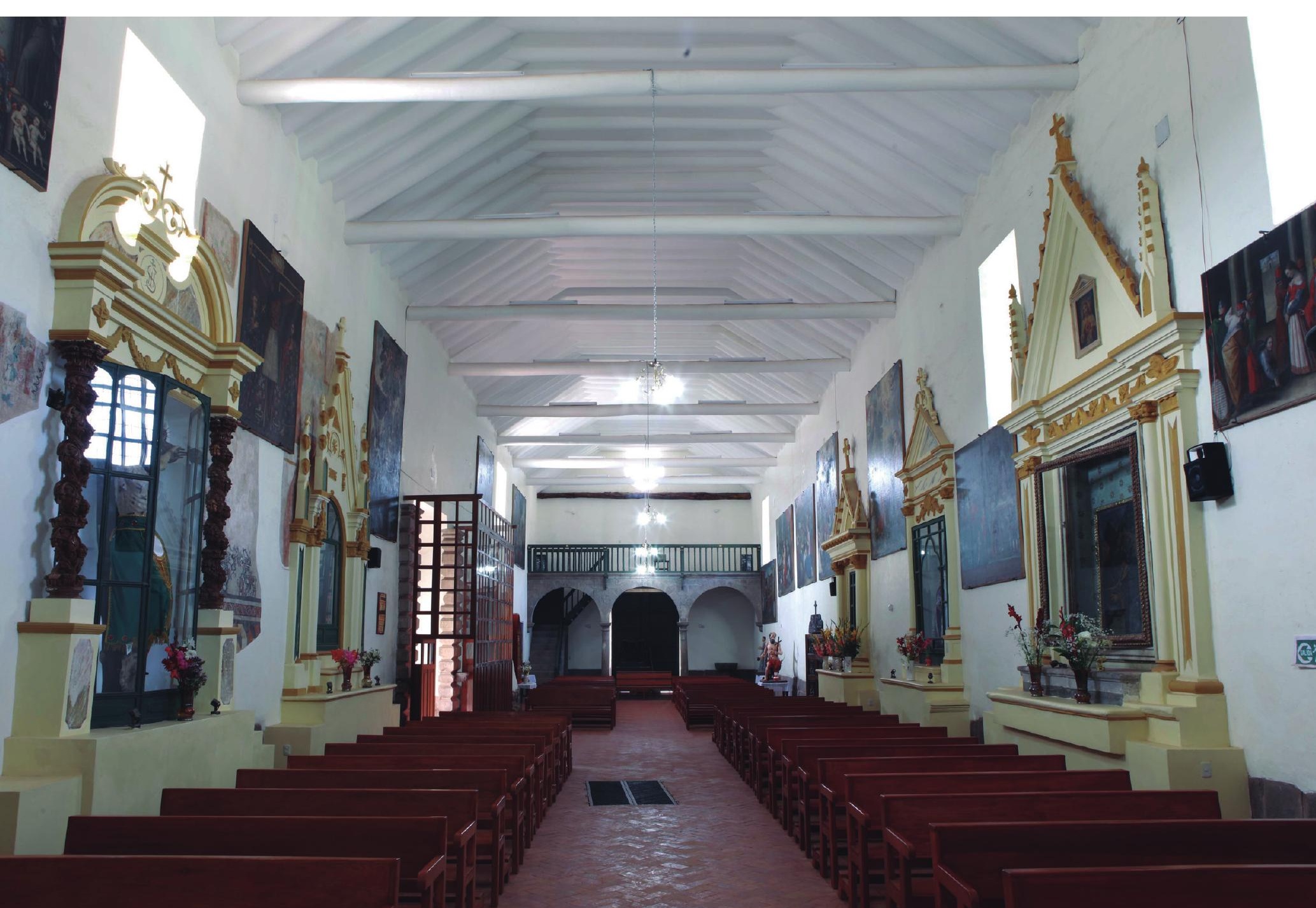




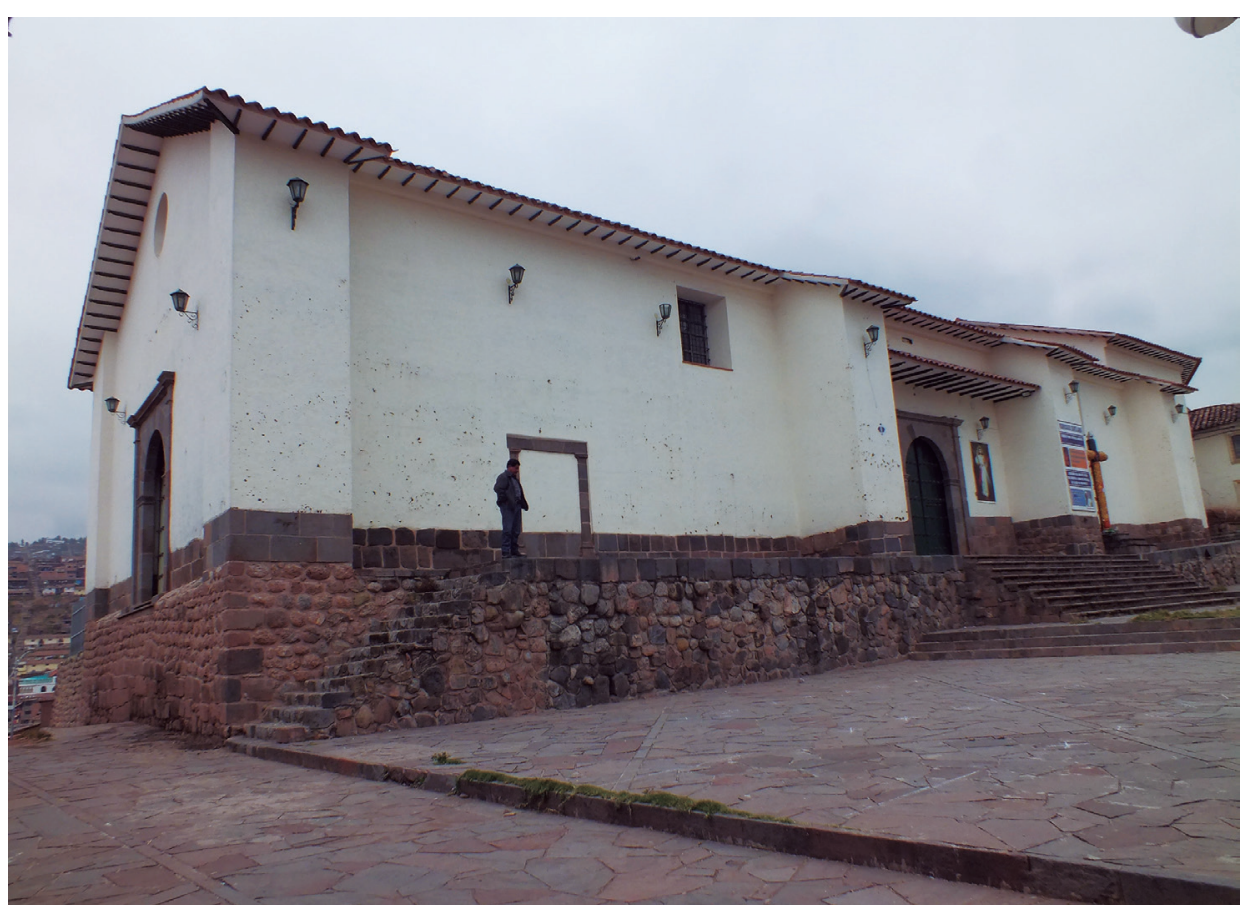

religiosas americanas, el atrio se concibió para el desarrollo de rituales al aire libre con el objeto de introducir al hombre andino en los contenidos y prácticas de la religión cristiana, aprovechando la arraigada costumbre y tradición de los cultos en espacios abiertos propios de la religión autóctona (Zecenarro, 2013b).

Como prolongación espacial del recinto religioso cristiano, para cumplir la función de cementerio -extensión del culto a los muertos que se practicaba en el antiguo Perú-, el templo de Santa Ana presentaba un atrio importante: allí se depositaban los cuerpos de todos los vecinos y residentes de la parroquia que por razones económicas no alcanzaban a conseguir una sepultura en los interiores del recinto religioso, privilegio de unos cuantos. Como lo atestigua el plano de 1643, se trató un espacio amplio y abierto definido por una barda con sendos arcos de ingreso y una cruz atrial, muy distinto al espacio urbano de la plaza que se situaba a su lado norte. Así funcionó por lo menos hasta mediados del siglo XIX, cuando se erradicó la costumbre de enterrar a los muertos en los contextos de los templos (Figura 20).

Sin realizar estudios previos y demostrando total desconocimiento de las características de la arquitectura religiosa de los siglos XVI y XVII, o quizás también por urgencias de orden político, en 1984 la autoridad municipal aprobó la construcción de un mercado barrial dentro del contexto del recinto sagrado. Primando sobre un análisis histórico y arquitectónico del monumento y su contexto, la decisión de la autoridad dio pie a la construcción de un bloque, inserto sobre el espacio abierto que correspondía al atrio del templo, confundiéndolo con el espacio urbano de la plaza. Esta intervención desconoció la existencia del atrio -como parte inherente del templo-, cuyas evidencias, por supuesto, para aquel entonces estaban totalmente soterradas. La absurda justificación de este hecho -según se indica- recaía en la necesidad de articular volumétricamente el templo con su torre exenta y la plaza con una de las calles adyacentes, acto que vulneraba todos los conceptos históricos y espaciales del diseño primigenio del conjunto arquitectónico.
Figura 18. Templo de Santa Ana después de la intervención (volumetría recuperada)

Fuente: Fotografía por Zecenarro Benavente, 2016. 
Figura 19. Esquema de la organización del conjunto religioso en el sector urbano de Karmenqa

Fuente: Elaboración propia, 2017.
Más aún, frente al olvido y descuido del espacio urbano de la plazoleta de Santa Ana -convertida en campo de juegos sobre un terraplén sin ningún tratamiento--, en 1993 la gestión municipal de aquel entonces inició también trabajos de remodelación, con lo que consolidó el mercado barrial como ente descongestionado del Mercado de San Pedro, hecho que nunca funcionó en la práctica. El bloque del mercado, construido de manera intrusiva sobre el espacio del atrio, jamás tuvo el uso planteado: inclusive hoy uno de sus ambientes alberga al Juzgado de Paz de Santa Ana, así como las instalaciones de la Institución Educativa Santa Ana N 448, ambas funciones incompatibles con la naturaleza del sitio. Gestiones municipales posteriores propusieron dotar de nuevos usos a esta infraestructura; incluso - de manera inconsulta y nada coherente- se planteó la construcción de servicios higiénicos en ese preciso lugar, que correspondió al desaparecido atrio del templo.

Tomando en consideración la dimensión histórica y arquitectónica del contexto mediato e inmediato del templo de Santa Ana, así como la necesidad de su recuperación integral, en el año 2009 la Municipalidad del Cusco, en convenio con la Agencia Española de Cooperación Internacional para el Desarrollo, planteó la rehabilitación integral y remodelación del espacio urbano de la plaza. Para ello, ya que incluía la recuperación del espacio del atrio, se debía demoler la infraestructura del mercado. Este proyecto se planteó como complemento a los trabajos de intervención restaurativa que el Instituto Nacional de Cultura venía realizando en aquella época en el contexto del templo.

Así, se programaron una serie de acciones orientadas al planteamiento del proyecto integral. Como acciones preliminares, en miras a enriquecer con datos históricos y arqueológicos la futura propuesta, la Municipalidad del Cusco, en coordinación con el

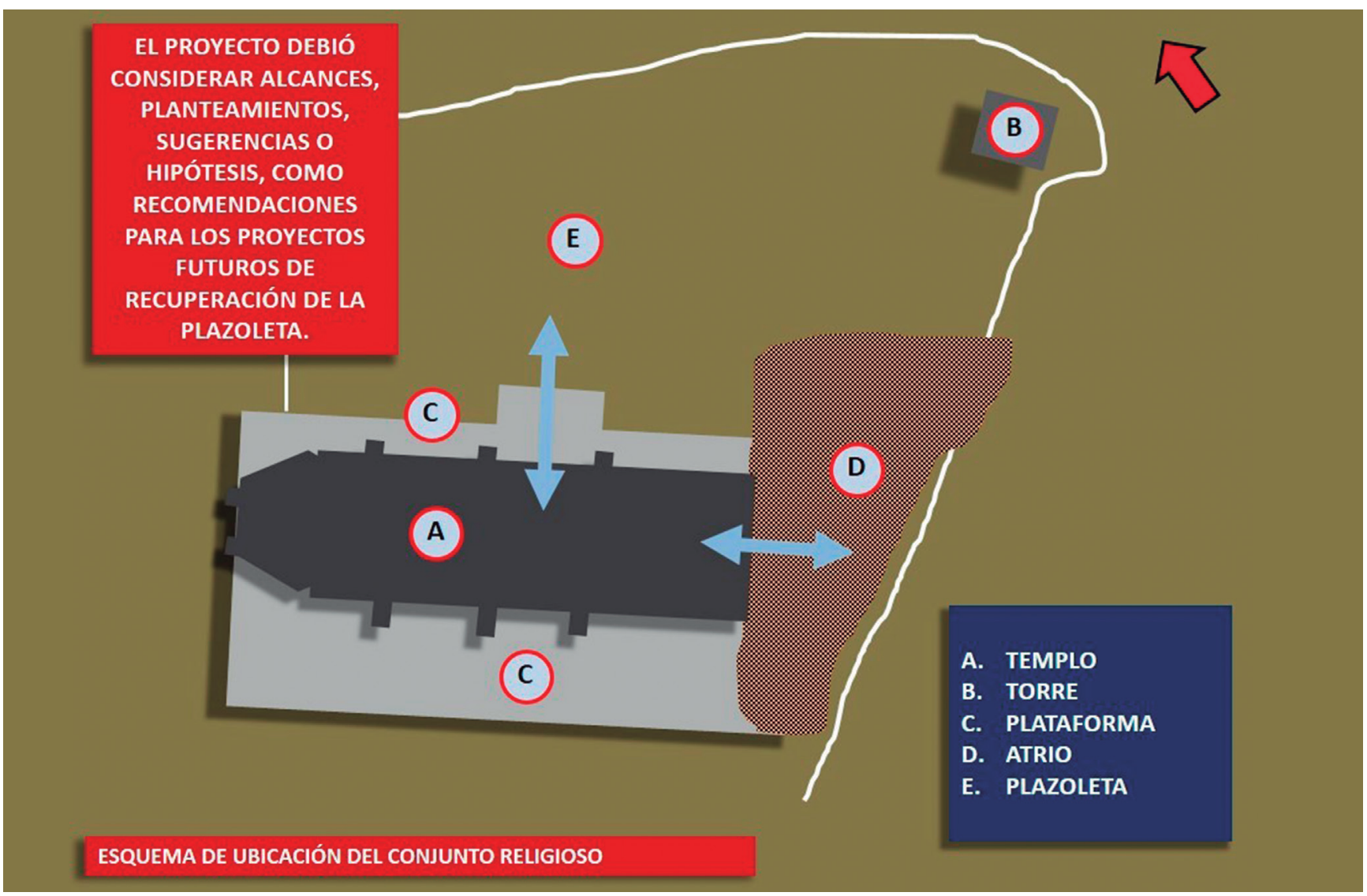




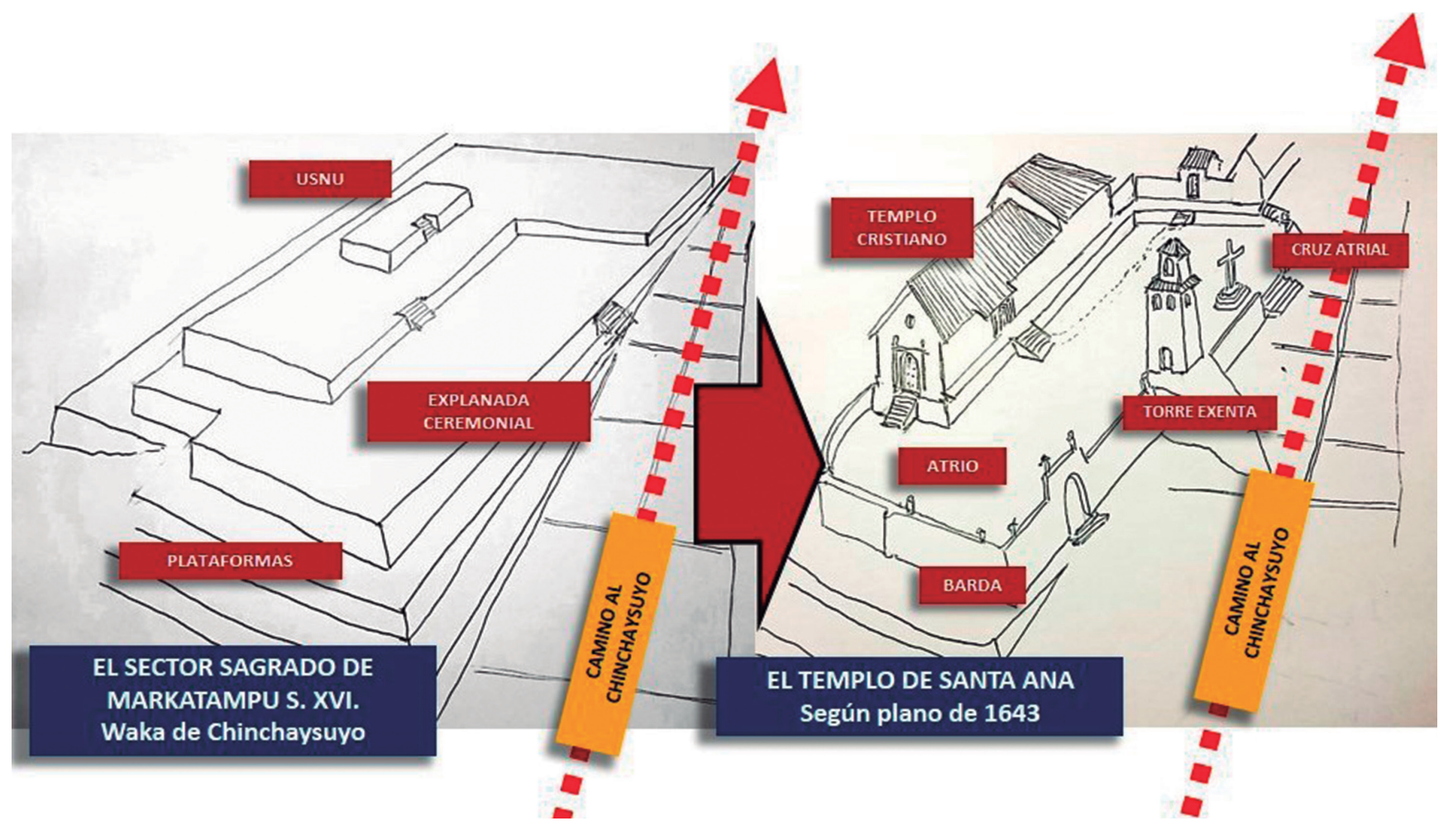

Instituto Nacional de Cultura, inició las investigaciones arqueológicas en los patios del edificio del mercado, construidos -como se ha indicado-sobre el atrio del templo. Los resultados fueron esclarecedores y contundentes, y demostraron la hipótesis principal de trabajo: que este espacio cumplió la función de cementerio. Efectivamente, el atrio del templo de Santa Ana albergó las tumbas de los feligreses durante el periodo virreinal, y la evidencia de ello se puso al descubierto durante los trabajos de investigación arqueológica efectuados en marzo de 2010 (Figura 21). Estos trabajos de exploración arqueológica reforzaron las intenciones de llevar adelante la remodelación del espacio urbano de la plazoleta, para recuperar y restituir el desparecido espacio del atrio. Lamentablemente, por las condiciones políticas, esta iniciativa quedó trunca.

Pese a los estudios históricos y arquitectónicos realizados, el Expediente Técnico Anual 2007. Restauración y Puesta en Valor del Monumento Histórico Artístico Templo de Santa Ana - Cusco no toma en cuenta la recuperación de este importante espacio del templo ni da alcances sobre la posible intervención del contexto inmediato, quizás porque se considera el área del atrio como parte del espacio público de la plaza de Santa Ana. En las propuestas de intervención, el planteamiento solamente incluye -a nivel de propuesta- la articulación del acceso de pies del templo con el exterior, mediante un sistema de escalinatas de piedra que, proyectadas hacia el espacio aparentemente público, salvan el marcado desnivel que en la actualidad se presenta, fruto de los distintos movimientos de tierra ocasionados por las intervenciones en el espacio urbano de este sector.

A la fecha (2016-2017), el Gobierno Municipal del Cusco ha vuelto a retomar la idea de recuperar el espacio urbano adyacente al templo de Santa Ana mediante el proyecto denominado Mejoramiento de la Plazoleta de Santa Ana, del barrio de Santa Ana, en el Centro Histórico del Cusco, Provincia de Cusco - Cusco. El proyecto considera, previo trabajo de socialización ya ejecutado, la demolición de la infraestructura del mercado. Si
Figura 20. Esquema síntesis del proceso evolutivo del conjunto religioso: Época inca e inicios del periodo virreinal (s. XVII)

Fuente: Elaboración propia, 2017. 


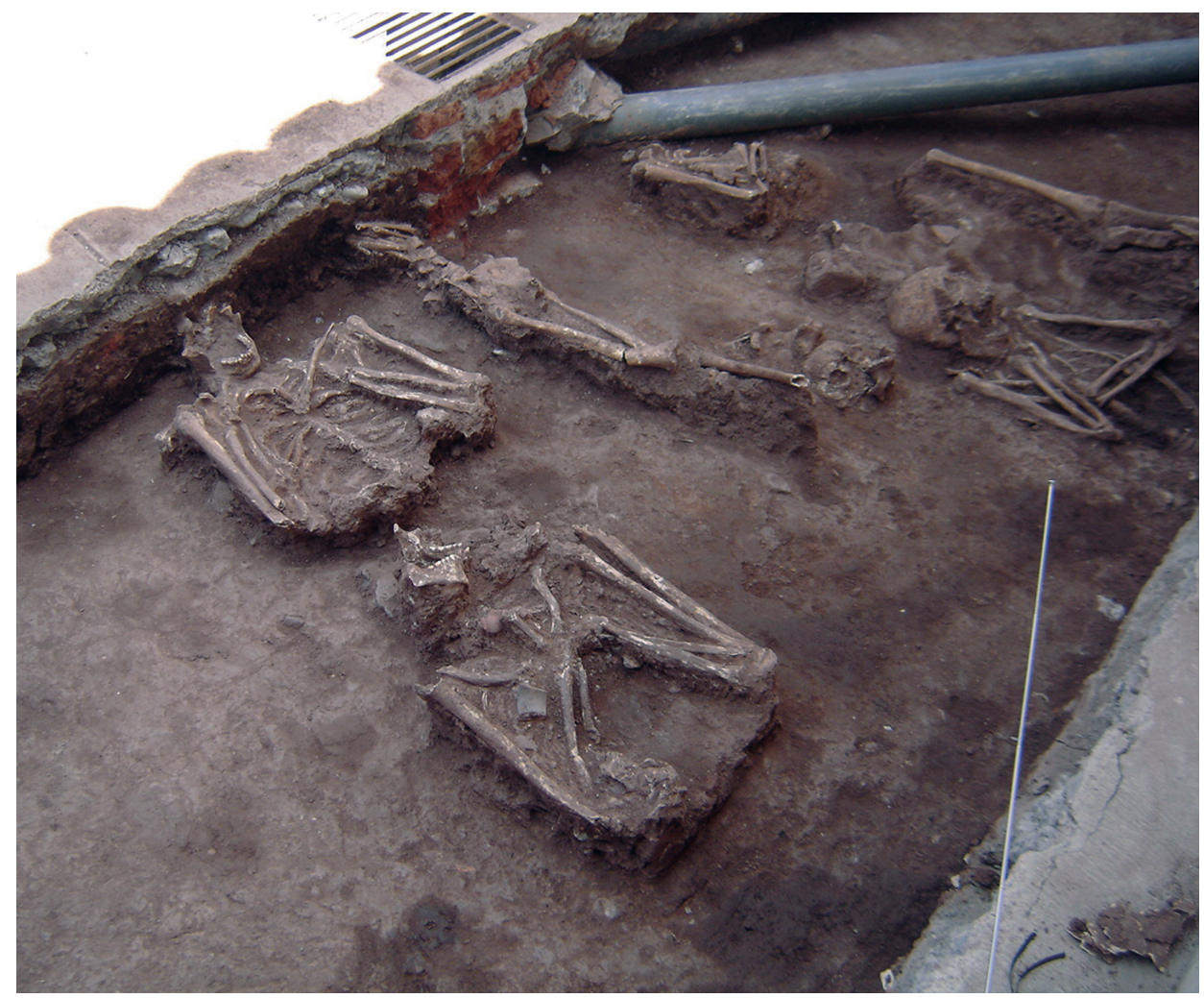

Figura 21. Contextos funerarios en el sector del atrio del templo. Exploraciones arqueológicas efectuadas en 2010

Fuente: Fotografía por Zecenarro Benavente, 2010. bien no contempla la restitución del atrio, al menos libera de este elemento ajeno el espacio que correspondió al conjunto arquitectónico del templo.

Al respecto, debieron considerarse por lo menos planteamientos teóricos, sugerencias o alternativas de intervención sobre la recuperación del espacio del atrio y su relación con el espacio público de la plaza de Santa Ana. Empleando los datos obtenidos gracias a las investigaciones arqueológicas, junto con estimados sobre la morfología del espacio del atrio, hubiera sido posible plantear algunas hipótesis sobre la forma original de este espacio y su manera de articularse con el espacio público. Estos alcances hubieran sido valiosos para definir cabalmente los lineamientos de intervención en el espacio público adyacente, proyecto integral que por ley le corresponde liderar a la autoridad municipal a través de las oficinas técnicas correspondientes (Figura 22).

\section{Conclusiones}

Por sus características constructivas y tipológicas, históricamente el templo de Santa Ana es uno de los ejemplos significativos de la arquitectura renacentista que con fines de la evangelización de los indígenas se implantó en el Cusco durante la segunda mitad del siglo XVI. Conserva sus cualidades formales y espaciales, al igual que los templos parroquiales de Santiago, San Cristóbal, San Blas, San Sebastián y San Jerónimo, por lo que se trata de un importante referente tipológico de la arquitectura religiosa anterior al sismo de 1650 .

8. En las fechas de realización de la presente investigación, los trabajos de obra estaban ya iniciados, pese a que el proyecto de intervención del espacio público Plazoleta Santa Ana no contaba aún con la aprobación del Ministerio de Cultura. Los reajustes al mismo se estaban realizando in situ, lo cual llama la atención pues no corresponde al debido proceso técnico y jurídico que concierne a un espacio considerado protegido e intangible. 


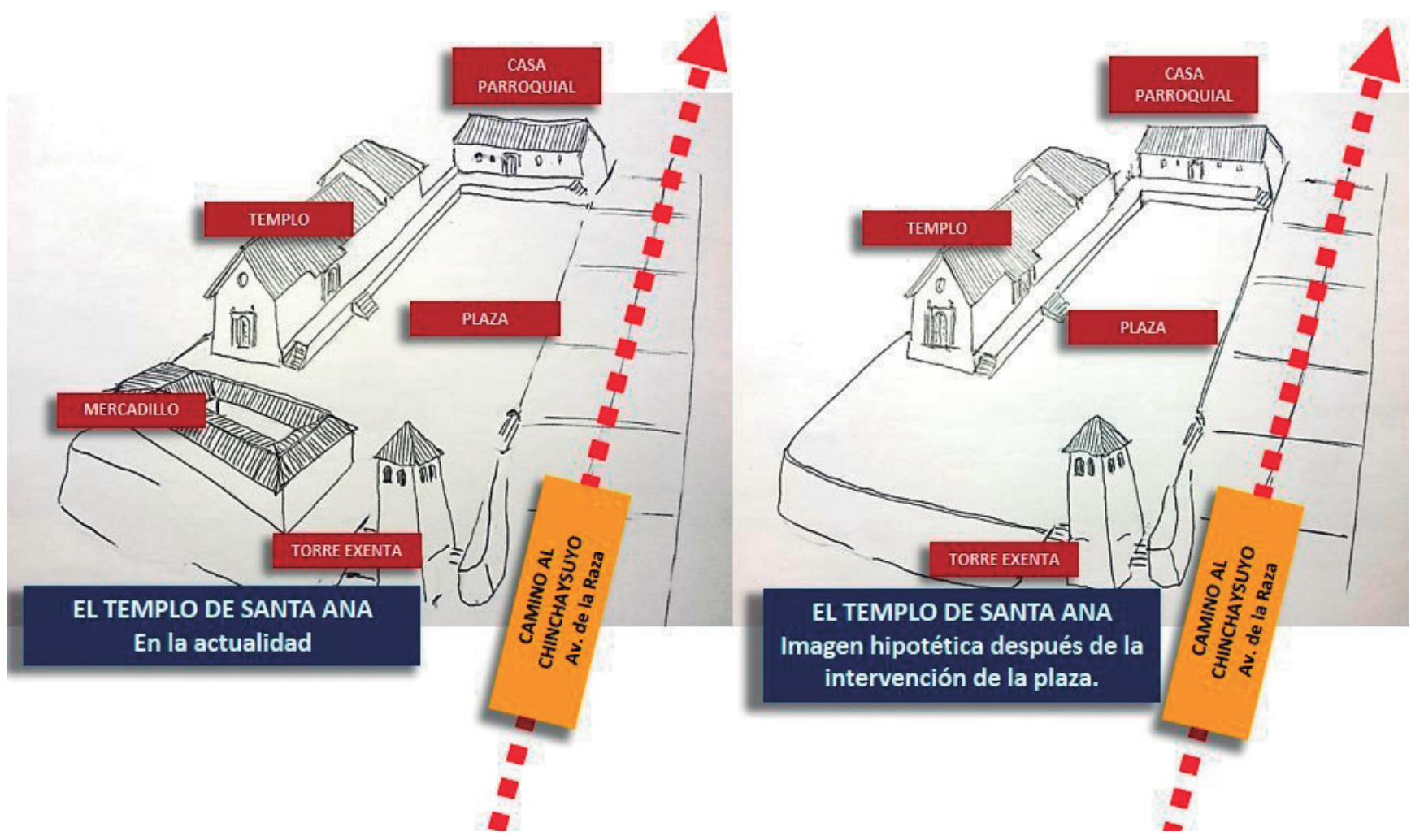

El proyecto integral de intervención que se llevó a cabo en este templo tuvo como propósito la conservación de sus características espaciales, estructurales y tipológicas, junto con la recuperación de los bienes muebles que complementan al edificio. El proyecto de intervención buscó la revalorización del monumento y su permanencia en el tiempo en función al ambiente urbano monumental donde está emplazado, es decir, el entorno mediato e inmediato (Guevara 2007), parte constitutiva del tejido urbano y social de este sector del Centro Histórico del Cusco (Figura 23).

Las obras efectuadas por el Ministerio de Cultura han devuelto fundamentalmente la lectura espacial de la nave, al restituir a la misma el espacio correspondiente al coro y el muro de pies. Esta restitución ha sido un proceso que se realizó desde la óptica de la restauración histórico-analítica y científica, a partir de decisiones tomadas sobre la base del estudio de documentos históricos, y evidencias físicas obtenidas mediante exploraciones arqueológicas y analogías formales.

Por otro lado, los procedimientos de restitución de las armaduras de par y nudillo de las cubiertas responden al criterio de la restauración estilística, ya que toma como evidencia el empleo de elementos análogos en edificaciones de la misma época, y así recupera la tradición constructiva mudéjar que caracteriza a estos testimonios. Lamentablemente, en este caso los criterios de autenticidad son discutibles, pues no se consideraron partes originales que pudieron haberse evidenciado mediante exploraciones arqueológicas.

De la misma forma, los trabajos de restitución de la portada de pies han tomado como referente estilístico los elementos originales de la portada lateral, sean molduras, bulas, etc. Quizás no se efectuó un estudio más profundo, el cual hubiese permitido evitar analogías o deducciones que concluyan en copias históricamente documentadas o falsos históricos. La reintegración de las bulas del portón de la portada lateral, acorde
Figura 22. El conjunto religioso de Santa Ana en la actualidad, y vista hipotética después de la intervención de la plaza

Fuente: Elaboración propia, 2017 


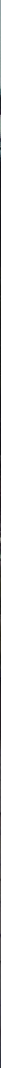

Figura 23. Templo de Santa Ana después de la intervención

Fuente: Fotografía por Zecenarro Benavente, 2016. a los principios de la restauración estilística, no consideró la necesaria distinción que debe existir entre los elementos originales restaurados y los restituidos.

Una notoria y discutible falla de dicho proyecto fue la omisión del desaparecido atrio del templo. Los trabajos de intervención solamente han tomado en cuenta la restauración del recinto religioso, mas no otros espacios que técnicamente le corresponden y forman parte del mismo, como el atrio, definido por bardas y demás elementos, y la misma cruz atrial -hoy puesta junto a los muros del templo-, que sí aparecen representados en el documento gráfico de 1643.

Pese a que este elemento arquitectónico es parte inherente de la tipología de los recintos religiosos renacentistas, solamente se realizó un trabajo aislado de investigación arqueológica en el contexto del atrio, experiencia llevada a cabo por iniciativa de la Municipalidad del Cusco, la Agencia Española de Cooperación Internacional y el Instituto Nacional de Cultura en el año 2010.

La restitución del espacio del atrio hubiera significado la recuperación de la integridad arquitectónico-figurativa de todo el conjunto monumental, principio metodológico y operativo que propugna la restauración crítica. Desafortunadamente, a la fecha existe en ejecución un proyecto de remodelación del espacio urbano de la plazoleta de Santa Ana, liderado por la autoridad municipal, el cual tiene como objetivo eliminar la estructura del mercado para liberar el espacio, de forma que funcione como mirador sobre la ciudad. Este proyecto contempla un diseño que involucra 
el espacio público que corresponde al atrio, elemento que desconoce. Por lo tanto, desarticula este importante componente de la arquitectura religiosa de la estructura del templo al cual pertenece.

Desde el punto de vista de la gestión, las intervenciones en el patrimonio edificado, realizadas según el modelo de gestión pública actual, desintegran al ambiente urbano monumental, porque su accionar se enfoca solo en unidades, con el objetivo de generar proyectos de inversión pública, sin considerar que la concepción del patrimonio urbano monumental es integral; es decir, monumento y espacio público constituyen una unidad inseparable, y cualquier intervención debe permitir la aplicación de Programas de Inversión Pública.

Sin embargo, desde el punto de vista de la recuperación de la imagen y el paisaje urbano del sector, la ejecución del Proyecto de Restauración y Puesta en Valor del Monumento Histórico Artístico del Templo de Santa Ana se complementa con el proyecto de mejoramiento de la plazoleta, ya que permitirá consolidar un circuito turístico en el sector, y así incrementar los recursos económicos de la población beneficiaria.

Finalmente, es importante incidir en el concepto de puesta en valor, el cual se menciona en el nombre del proyecto de intervención, y de manera implícita en los objetivos del mismo. Efectivamente, la puesta en valor y restauración del templo de Santa Ana implica la intervención directa sobre el bien patrimonial, con la intención de conservar sus condiciones materiales en el tiempo, pero involucrando a la población a través de un uso o función asignado - de naturaleza compatible-, que en el caso de esta infraestructura es el culto religioso, función que sigue vigente desde el siglo XVI. Esta continuidad en el uso o función -apropiada por la población y asimilada a su propia memoria- contribuye a proteger y recuperar este patrimonio en sus mejores condiciones de autenticidad, garantiza su permanencia en el tiempo y, además, genera beneficios sociales y económicos para la sociedad en general, y, por ende, desarrollo (Figura 24).

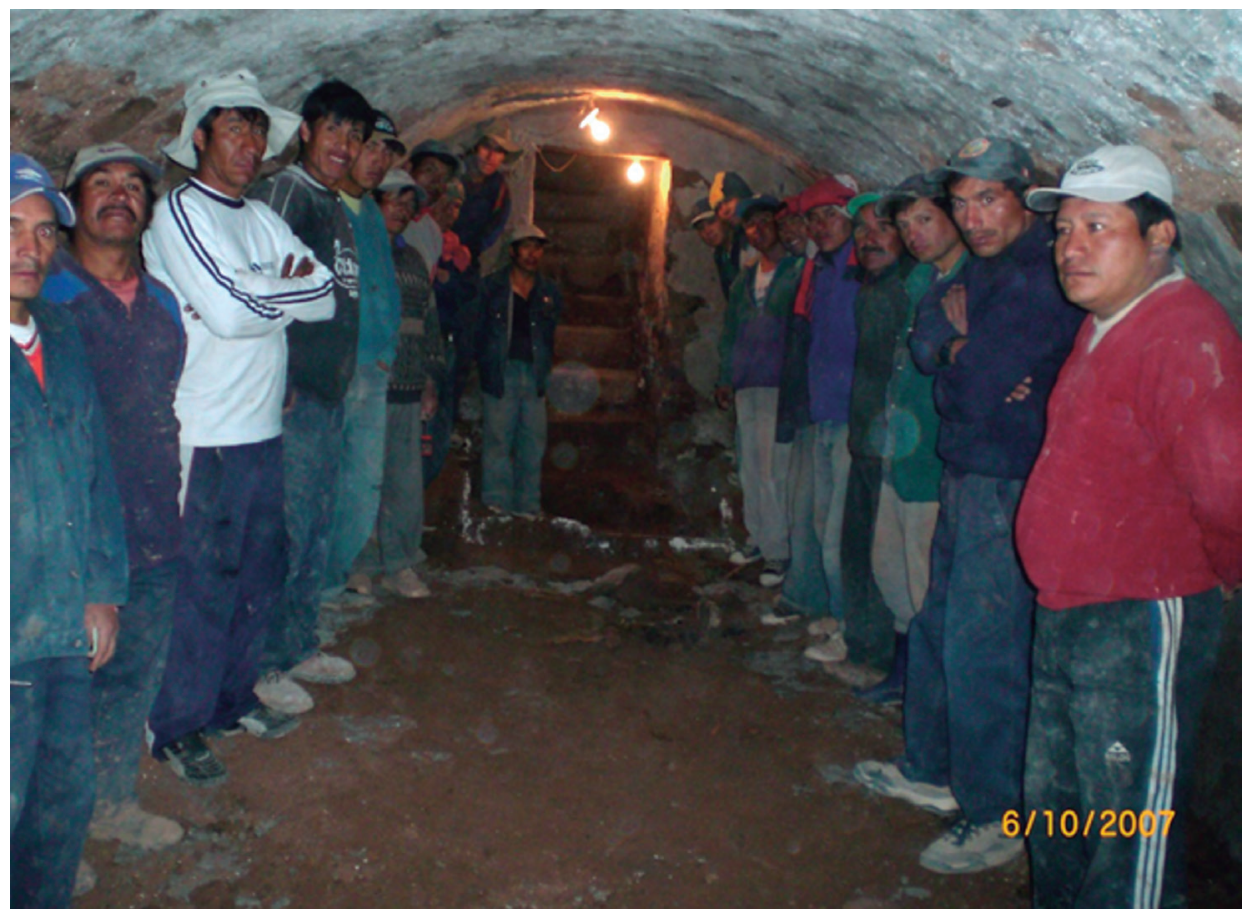

Figura 24. Personal técnico de la obra de restauración del Templo de Santa Ana

Fuente: Fotografía por Guevara Boza, 2007. 


\section{Recomendaciones}

Los aspectos señalados sobre la experiencia restaurativa desarrollada en el templo de Santa Ana y la obra de remodelación de su entorno urbano adyacente permiten plantear tres factores que deberían considerarse al realizar intervenciones similares: a) los temas de investigación histórica, arquitectónica, urbana y tecnológica; b) la implicancia del modelo de gestión utilizado; y c) la coordinación interinstitucional y la influencia de las decisiones políticas.

Con el objetivo de conservar y garantizar la autenticidad de los testimonios materia de intervención, se recomienda que las obras de restauración se fundamenten en la investigación histórica y arquitectónica sobre el bien patrimonial, considerando la singularidad que este representa como testimonio único e irrepetible. Los resultados de la intervención física deben reflejar este esfuerzo, y evitar emplear los métodos de la restauración estilística o recaer en la generación de falsos históricos.

La experiencia en conservación y restauración del patrimonio edificado en Cusco es vasta; sus alcances y logros han trascendido fronteras. Sin embargo, como en el presente caso, muchas veces la gestión enfocada en la recuperación patrimonial que precede a las acciones técnicas no es considerada cabalmente por las entidades responsables, lo que deriva en resultados no siempre acertados, que van en desmedro de los valores que los propios proyectos intentan recuperar. El criterio de emplear el modelo de gestión para la inversión pública (SNIP) solamente desde la perspectiva de los proyectos de inversión pública (PIP), aplicada a experiencias de conservación y restauración del patrimonio edificado, no ha sido nada coherente con la naturaleza de los bienes patrimoniales.

En el caso del templo de Santa Ana, no se tomó en cuenta sus elementos constitutivos esenciales como una unidad, lo cual generó una intervención desarticulada que ha ponderado la recuperación del recinto religioso sin considerar el atrio y su relación con el espacio urbano adyacente. Para futuros casos similares, se espera que esta situación cambie, gracias a la aplicación del nuevo modelo de gestión de inversiones (INVIERTE. $\mathrm{PE}$ ). Se recomienda la generación de programas de intervención que consideren al patrimonio como una entidad integral que tiene distintos componentes y escalas ${ }^{9}$.

Finalmente, el hecho de no contar con proyectos gestados bajo programas integrales de desarrollo hace que estos sean vulnerables a decisiones políticas unilaterales producto del trabajo no siempre coordinado entre las instituciones responsables. Las acciones sobre el patrimonio edificado deben partir de lineamientos y políticas que involucren la acción concertada y participativa de sus instituciones tutelares, papel que protagonizan en este caso el Ministerio de Cultura y la Municipalidad del Cusco, los cuales, coordinando con las instituciones representativas de la sociedad, las empresas prestadoras de servicios y fundamentalmente con la población organizada -heredera y depositaria de todos los beneficios-, deben diseñar y ejecutar metodologías integrales y coherentes, cuyos resultados solventen el desarrollo de la sociedad, ya que estas acciones constituyen palancas de bienestar y fortalecimiento de identidad.

Entre los años 2000 y 2012, mediante un convenio entre la Municipalidad del Cusco y la Agencia Española de Cooperación Internacional, se intervinieron ambientes urbanos y edificios patrimoniales del Centro Histórico, acciones que incluyeron la participación directa del Instituto Nacional de Cultura -hoy Ministerio de Cultura-. En el periodo señalado se consolidaron, de acuerdo a un modelo de gestión liderado por la municipalidad, una serie de metodologías que involucraron el concurso de la sociedad

9. Las intervenciones deben considerar desde obras de ornato y equipamiento urbano en espacios adyacentes o áreas comprometidas hasta intervenciones en monumentos, conjuntos monumentales, ambientes urbano-monumentales, sitios y centros históricos, o paisajes culturales. 
organizada y sus instituciones, experiencia que debe ser tomada en cuenta, replicada y perfeccionada, de forma que junto a programas de sensibilización continua ${ }^{10}$ oriente su accionar a la recuperación del patrimonio y su tejido social en el marco del respeto y la consolidación de la memoria colectiva.

Con todo lo señalado, se recomienda que la experiencia de la restauración del templo de Santa Ana se complemente y concluya con acciones integrales producto de la concertación de las dos instituciones tutelares, cuya decisión permita la recuperación integral del monumento y su respectivo ambiente urbano monumental para la sociedad y la ciudad, así como la revaloración de sus características históricas, arquitectónicas, urbanas y ambientales.

\section{Referencias}

Amado, D. (2009). Ocho parroquias cuzqueñas. Cusco, Perú: Proyecto Qhapaq Ñan, Instituto Nacional de Cultura.

Ángles, V. (1983). Historia del Cusco (Cusco colonial). Lima, Perú: Industrial Gráfica.

Barreda, L. (1991). Historia y arqueología del Qosqo pre-inka. Revista Municipal del Qosqo, 2, 20-36.

Bauer, B. (2000). Archivos de Historia Andina 33: El espacio sagrado de los Incas. El sistema de ceques del Cuzco. Cuzco, Perú: Centro de Estudios Regionales Andinos Bartolomé de las Casas.

Benavente, T. (1995). Historia del arte cusqueño. Pintores cusqueños de la Colonia. Cusco, Perú: Municipalidad del Qosqo.

Benavente, T. (2006). Historia del arte cusqueño. Imaginería o escultura religiosa cusqueña de los siglos XVI, XVII y XVIII. Lima, Perú: Publicación Familia Benavente Gutiérrez.

Blanco, J. M. (1974). Diario del viaje del Presidente Orbegoso al Sur del Perú. Lima, Perú: Universidad Católica del Perú.

Brandi, C. (1977). Teoría de la restauración. Turín, Italia: Alianza Editorial.

Carrillo, A. (2013). Conceptos. Conservación restauración. La Catedral del Cusco. Cusco, Perú: Ministerio de Cultura.

Convenio Facultad de Arquitectura, Urbanismo y Artes - Universidad Nacional de Ingeniería \& Fundación Ford (1994). Inventario del Patrimonio Monumental Inmueble - Cusco. Lima, Perú: Universidad Nacional de Ingeniería.

Chanfón, C. (1983). Fundamentos teóricos de la restauración. México D.F., México: Universidad Autónoma de México.

De la Plaza Escudero, L. (2012). Diccionario visual de términos arquitectónicos. Madrid, España: Cátedra.

González, A. (1999). Memoria SPAL 1993-1998. La restauración objetiva (Método SCCM de restauración monumental. Barcelona, España: Institut d'Edicions de la Diputació de Barcelona.

González-Varas, I. (2008). Conservación de bienes culturales. Teoría, historia, principios y normas. Madrid, España: Cátedra.

Guevara, E. B. (2007). Expediente técnico anual 2007. Restauración y puesta en valor del monumento histórico artístico Templo de Santa Ana - Cusco. Cusco, Perú: Dirección Regional de Cultura.

Hayakawa, J. (2010). Gestión del patrimonio cultural y centros históricos latinoamericanos. Tendiendo puentes entre el patrimonio y la ciudad. Lima, Perú: Universidad Nacional de Ingeniería.

Instituto Nacional de Cultura. (1989). Cartas internacionales de conservación del patrimonio cultural. Cusco, Perú: Jefatura de la Unidad de Investigación. Dirección de Patrimonio Cultural Monumental. Dirección de Actividades Culturales.

10. La sensibilización debe considerarse parte integral de los proyectos de inversión pública. Actualmente, con mucho éxito, este factor forma parte de las intervenciones de conservación del patrimonio orientadas a capacitar a la población beneficiaria. 
devenir VOL. 4, Nº7, ENERO - JUNIO 2017, PP. 117-144 - EsTUDIOS I ISSN 2312-7562

UNIVERSIDAD NACIONAL DE INGENIERÍ, LIMA

Mesa, J. \& Gisbert, T. (2002). Monumentos de Bolivia. La Paz, Bolivia: Gisbert.

Municipalidad del Cusco (2010). Cusco monumental. Ombligo del mundo. Lima, Perú: Navarrete.

Muñoz, S. (2003). Teoría contemporánea de la restauración. Madrid, España: Síntesis.

Vidal, H. (1958). Visión del Cusco. Monografía sintética. Cusco, Perú: Garcilaso.

Villanueva, H. (1989). Cuzco monumental. La imperial ciudad de los incas en la obra de un mecenas. Cusco, Perú: Instituto Nacional de Cultura.

Zecenarro, G. (2004). Saywas y suqanqas. Usnus y asientos del Sol. Instrumentos de medición astronómica prehispánica. Arkinka, 9(106), 86-98.

Zecenarro, G. (2005). Las Wakas. Dioses y Santuarios del Cusco prehispánico. Waka XXI, 1(2), 76-82.

Zecenarro, G. (Ed.). (2007). Cusco monumental. Arquitectura cusqueña, monumentos religiosos y civiles del Cusco. Cusco, Perú: Municipalidad del Cusco.

Zecenarro, G. (2013a). Arte barroco. La pintura cusqueña. La escultura colonial cusqueña. En Municipalidad del Cusco (Eds.), Cusco y la herencia del barroco andino (pp. 200-297). Lima, Perú: Navarrete.

Zecenarro, G. (2013b). Por la ruta del barroco cusqueño. Lima, Perú: Cartolan. 